\title{
Report of the Workshop on Nuclear Facility Design Information Examination and Verification for Safeguards
}

Philip Casey Durst Michael Ehinger

Richard Metcalf

Robert Bean

Trond Bjornard

Brian Boyer

Morgan Burks

Arden Dougan

Brian Smith

Michael Watkins
Doug Few

David Hanks

Greg Lancaster

Kelly Michel

Lucian Mihailescu

Jim Morgan

Keith Tolk

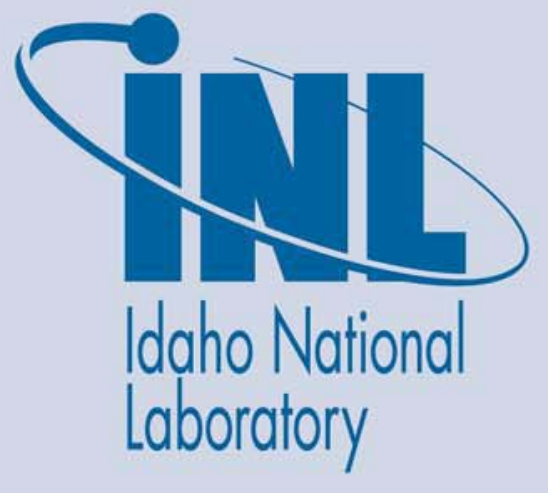

\section{October 2009}

The INL is a U.S. Department of Energy National Laboratory operated by Battelle Energy Alliance 


\title{
Report of the Workshop on Nuclear Facility Design Information Examination and Verification for Safeguards
}

\author{
Philip Casey Durst \\ Richard Metcalf \\ Robert Bean \\ Trond Bjornard \\ Brian Boyer $^{1}$ \\ Morgan Burks ${ }^{2}$ \\ Arden Dougan ${ }^{2}$ \\ Michael Ehinger ${ }^{3}$ \\ Doug Few \\ David Hanks ${ }^{4}$ \\ Greg Lancaster \\ Kelly Michel ${ }^{1}$ \\ Lucian Mihailescu ${ }^{5}$ \\ Jim Morgan ${ }^{3}$ \\ Brian Smith $^{6}$ \\ Keith Tolk ${ }^{7}$ \\ Michael Watkins ${ }^{6}$
}

${ }^{1}$ LANL

${ }^{2}$ LLNL

${ }^{3}$ ORNL

${ }^{4}$ SRNL

${ }^{5}$ LBNL

${ }^{6}$ PNNL

${ }^{7}$ SNL

October 2009

\section{Idaho National Laboratory \\ Idaho Falls, Idaho 83415}

http://www.inl.gov

Prepared for the

U.S. Department of Energy

Office of National Nuclear Security Administration

Office of NA-243

Under DOE Idaho Operations Office

Contract DE-AC07-05ID14517 


\section{DISCLAIMER}

This report was prepared as an account of work sponsored by an agency of the U.S. Government. Neither the U.S. Government nor any agency thereof, nor any of their employees, makes any warranty, expressed or implied, or assumes any legal liability or responsibility for the accuracy, completeness, or usefulness, of any information, apparatus, product, or process disclosed, or represents that its use would not infringe privately owned rights. References herein to any specific commercial product, process, or service by trade name, trade mark, manufacturer, or otherwise, does not necessarily constitute or imply its endorsement, recommendation, or favoring by the U.S. Government or any agency thereof. The views and opinions of authors expressed herein do not necessarily state or reflect those of the U.S. Government or any agency thereof. 
Prepared for the

U.S. Department of Energy,

National Nuclear Security Administration

Office of NA-243

Under DOE Idaho Operations Office

Contract DE-AC07-05ID14517 


\section{EXECUTIVE SUMMARY}

The International Atomic Energy Agency (IAEA) implements nuclear safeguards and verifies countries are compliant with their international nuclear safeguards agreements. ${ }^{a}$ One of the key provisions in the safeguards agreement is the requirement that the country provide nuclear facility design and operating information to the IAEA relevant to safeguarding the facility, and at a very early stage. ${ }^{\mathrm{b}, \mathrm{c}}$ This provides the opportunity for the IAEA to verify the safeguards-relevant features of the facility and to periodically ensure that those features have not changed. The national authorities (State System of Accounting for and Control of Nuclear Material - SSAC) provide the design information for all facilities within a country to the IAEA. The design information is conveyed using the IAEA's Design Information Questionnaire (DIQ) and specifies: (1) Identification of the facility's general character, purpose, capacity, and location; (2) Description of the facility's layout and nuclear material form, location, and flow;

(3) Description of the features relating to nuclear material accounting, containment, and surveillance; and (4) Description of existing and proposed procedures for nuclear material accounting and control, with identification of nuclear material balance areas. The DIQ is updated as required by written addendum. IAEA safeguards inspectors examine and verify this information in design information examination (DIE) and design information verification (DIV) activities to confirm that the facility has been constructed or is being operated as declared by the facility operator and national authorities, and to develop a suitable safeguards approach.

Under the Next Generation Safeguards Initiative (NGSI), the National Nuclear Security Administrations (NNSA) Office of Non-Proliferation and International Security identified the need for more effective and efficient verification of design information by the IAEA for improving international safeguards in the future. Consequently, the NNSA Office of International Regimes and Agreements (NA243) sponsored a team of U.S. Department of Energy National Laboratory nuclear safeguards experts and technologists to conduct a workshop on methods and technologies for improving this activity, under the ASA-100 Advanced Safeguards Approaches Project. The workshop focused on reviewing and discussing the fundamental safeguards needs, and presented technology and/or methods that could potentially address those needs more effectively and efficiently.

\section{From this workshop the Team concluded the following:}

- The DIE/DIV activity remains an important safeguards measure used by the IAEA to verify that nuclear facilities are being built and operated by the facility operator as declared by the national authorities, i.e., that the facility function or capacity has not been altered.

\footnotetext{
${ }^{\text {a }}$ In accordance with Article III.1 of the Treaty on the Non-Proliferation of Nuclear Weapons (NPT), non-nuclear-weapons states are obligated to conclude a comprehensive safeguards agreement (CSA) that contains an, "an undertaking by the State to accept safeguards, in accordance with the terms of the Agreement on all source or special fissionable material in all peaceful nuclear activities within its territory, under its jurisdiction, or carried out under its control anywhere, for the exclusive purpose of verifying that such material is not diverted to nuclear weapons or other explosive devices." (Sources - IAEA INFCIRC/153 (corrected) and NPT)

${ }^{\mathrm{b}}$ According to a 1992 IAEA Board of Governors decision, all parties to comprehensive safeguards agreements are required to inform the IAEA of their programs for new nuclear facilities and activities as soon as the decision to construct the new facility has been taken. In April of 1992, "the Board called upon all parties to comprehensive safeguards agreements...to inform the Agency of their programmes for new nuclear facilities and activities, and for any modifications to existing facilities through the provision of preliminary design information, as soon as the decision to construct, to authorize construction, or modify has been taken." (Source - IAEA Board of Governors Report, GOV/2554/Attachment 2, April, 1992)

${ }^{\mathrm{c}}$ The providing of nuclear facility design information is required under both comprehensive safeguards agreements (INFCIRC/153-type) and INFCIRC/66-type agreements. Under an INFCIRC/66-type safeguards agreement, the state is to provide design information on principal nuclear facilities to enable the IAEA to perform the design review at as early stage as possible. (Sources - IAEA Safeguards Glossary, 2001 Edition, and INFCIRC/66, para. 31 and 32)
} 
- As currently conducted by the IAEA, the DIE/DIV activity could be made more efficient and effective.

- The DIE/DIV activity relies heavily on individual inspector training, knowledge, and experience. In the near-term, additional training could help standardize the conduct of the DIE/DIV. Tools such as the 3DLR also help standardize the conduct and improve the effectiveness of the DIE/DIV in detecting safeguards relevant changes. However, the IAEA only has three 3DLR units, one of which is permanently stationed at the Rokkashomura Reprocessing Plant in Japan. Additionally, the IAEA has only the older Mark-I 3DLR (ca. 2003) and none of the newer Mark-II (2008) models.

- As nuclear facilities become larger and more complex, the IAEA must be able to perform DIE/DIV more efficiently to verify that the safeguards relevant features of the facility are as declared by the facility operator and national authorities. This was one of the major conclusions from the 10-year effort of performing DIE/DIV at the Rokkashomura Reprocessing Plant (RRP) in Japan.

- IAEA inspectors need to have ready access to design information and previous DIE/DIV reports in the field while performing the DIE/DIV. This need could potentially be met with portable laptop or tablet personal computers containing the design information on a secured and protected file.

- IAEA inspectors need to be able to discern and detect safeguards relevant changes to the nuclear facility during the DIE/DIV activity. This need could be met in the near term with additional training, and potentially in the future with new tools that incorporate automated image recognition and built-in change detection software (CDS), such as utilized by the 3DLR. The image recognition feature could also embody an automated and accessible computerized catalogue of known equipment types and features to aid in this process.

- The IAEA needs the ability to detect concealed process equipment and piping, which could potentially be detected during DIE/DIV if the right tools were available. Development efforts have focused on combining the 3DLR with a gamma camera to detect undeclared process piping and nuclear material. The use of enhanced ground penetrating radar (GPR) is also possible, as had been demonstrated in detecting buried waste drums and vessels at the DOE Hanford Site. This is still an area that requires additional development and demonstration to prove that the tool could be used practically by the IAEA for DIE/DIV.

- The DIE/DIV activity is based fundamentally on the quality of the information provided by the facility operator through the SSAC to the IAEA in the form of the IAEA DIQ. U.S. DOE had previously provided model responses and examples to the IAEA, to help standardize the process and raise the quality of the information provided via the DIQ. These models are now thirty years old and are in need of being updated.

- The DIE/DIV activity depends on the IAEA Safeguards Facility Officer maintaining a current and relevant Essential Equipment List (EEL) of safeguards relevant equipment at the facility.

Based on the workshop findings and conclusions, the Team recommends the following next steps to NNSA, in order of priority, to help the IAEA improve the effectiveness and efficiency of the DIE/DIV activity:

Near Term - (Within the next 6 Months to 1 Year)

- Provide additional training via the United States Support Program to the IAEA (USSP) to help IAEA safeguards inspectors read mechanical, piping, instrument, and architectural blueprints, engineering drawings, and process flow schematics more proficiently. The estimated cost of providing additional training to the IAEA inspectors in the reading of engineering blueprints is $\$ 100 \mathrm{~K}$ for one year. 
- Provide financial support to the IAEA to upgrade the three existing 3DLR units from the Mark-I (2003) model to the Mark-II (2008) model. According to the system developer/integrator from JRC/Ispra, the cost of this upgrade is estimated to be on the order of $\$ 50 \mathrm{~K}$ per unit, for a one time total cost of $\$ 150 \mathrm{~K}$.

- Provide financial support to the IAEA to acquire additional Mark-II 3DLR units. If the IAEA had three additional 3DLR units, one unit could be prepositioned in each major region of the world where the IAEA inspects. This would reduce the cost of shipping 3DLR units to and from Vienna, and would minimize the likelihood of damage resulting from shipping. At an estimated cost of $\$ 200 \mathrm{~K}$ per unit, the total cost would be $\$ 600 \mathrm{~K}$.

- Provide additional training via the USSP to the IAEA in the use of the new Mark-II 3DLR. Of the estimated 40 safeguards inspectors trained in the use of the 3DLR, most were trained in the use of the older Mark-I model, and of those, as many as 10 have left the IAEA. The IAEA needs intense training in the use of the Mark-II model so that use of the 3DLR is not hindered for lack of trained personnel. It is recommended that this training be provided by knowledgeable staff at JRC/Ispra, with the support of experienced DOE National Laboratory staff. The estimated cost of providing additional training to the IAEA in using the Mark-II 3DLR and training a larger group of inspectors is $\$ 100 \mathrm{~K}$ for one year.

- Provide updated model responses to the IAEA DIQ through the United States Support Program to the IAEA, for each major type of nuclear facility, as had been provided previously in 1979. The estimated cost for updating the model responses to the IAEA DIQ for the 10 major types of nuclear facilities is $\$ 100 \mathrm{~K}$ total.

- Recommend to the IAEA Department of Safeguards to update the Essential Equipment Lists (EEL) for facilities under IAEA safeguards.

- Recommend to the IAEA that they systematically digitize old design information, such as Polaroid photographs, and implement the use of Change Detection Software (CDS). If the older reference information were digitized, it could be stored on resident laptop computers, and/or hard disks at the facility under seal. It could subsequently be compared to new digital photos acquired during current DIE/DIV activities to detect safeguards relevant changes, using the CDS. This process would be far less subjective and more systematic than the use of hardcopy photos and individual inspector visual observation. The estimated cost of demonstrating CDS to support DIE/DIV for a group of three nuclear facilities is $\$ 50 \mathrm{~K}$.

Medium Term - (Within 1 to 3 Years)

- Fund the National Laboratories to demonstrate the use of the JRC-developed Outdoor Verification System (OVS) in a practical DIE/DIV exercise to verify an entire nuclear site. The purpose of the demonstration would be to show the utility of the OVS in verifying complete nuclear sites and detecting the functional linkage between nuclear and ancillary facilities. The estimated cost of demonstrating the OVS to support DIE/DIV at a DOE nuclear site is $\$ 100 \mathrm{~K}$.

- Fund the National Laboratories to demonstrate a modified 3DLR with gamma camera (Gamma LIDAR) in a practical DIE/DIV exercise at a DOE National Laboratory facility. The demonstration should be conducted in a lifelike DIE/DIV scenario to detect undeclared process piping or vessels handling radioactive material. The estimated cost of further developing and demonstrating the Gamma LIDAR in support of DIE/DIV is $\$ 500 \mathrm{~K}$.

- Fund the National Laboratories to demonstrate the use of enhanced ground penetrating radar (GPR) in a practical DIE/DIV exercise at a DOE National Laboratory facility. The demonstration should be conducted in a lifelike DIE/DIV scenario to detect concealed process piping in concrete walls and undeclared piping and vessels buried within 1-3 meters of top soil. The estimated cost of developing and demonstrating enhanced GPR in support of DIE/DIV is $\$ 500 \mathrm{~K}$. 
- Consider funding the National Laboratories to develop a portable heads-up viewer for conducting DIE/DIV. The need for such a device would need to be affirmed by the IAEA, but it is technically possible to develop a headset that captures digital images by the wearer and compares these images against the computerized reference files for the facility to detect safeguards relevant features and changes, using change detection software (CDS). The heads-up viewer could also incorporate a radiation detector/personnel dosimeter that would allow the user to detect and confirm the presence of high-radiation fields, which would protect the inspector when the facility is hot and operational. The estimated cost of developing and demonstrating a portable heads-up viewer to support DIE/DIV is estimated at $\$ 300 \mathrm{~K}$. 


\section{ACKNOWLEDGEMENTS}

Funding for this workshop and preparation of the report was provided by the U.S. DOE NNSA Office of International Regimes and Agreements (NA-243) under the Advanced Safeguard Approaches (ASA-100) Project in support of the Next Generation Safeguards Initiative (NGSI). The Workshop Team wishes to thank the Office of NA-243 for their support, input, and direction in preparing this report. The Team also wishes to thank INL for hosting the workshop, providing the meeting facilities, and tour of the pyro reprocessing Fuel Conditioning Facility (FCF). The authors want to thank Gordon Holt for editing the final report. 
(This page left intentionally blank) 


\section{CONTENTS}

EXECUTIVE SUMMARY .iii

ACKNOWLEDGEMENTS vii

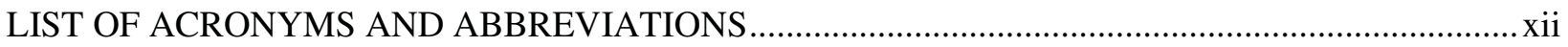

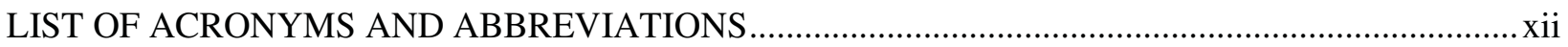

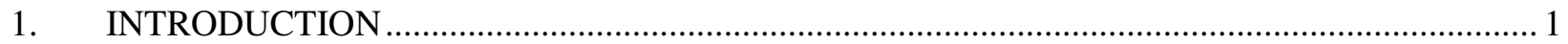

1.1 Design Information Examination and Verification for Safeguards......................................... 1

1.2 Purpose of the DIE/DIV Technical Workshop ................................................................... 3

2. REVIEW OF CURRENT DIE/DIV SAFEGUARDS NEEDS …........................................... 4

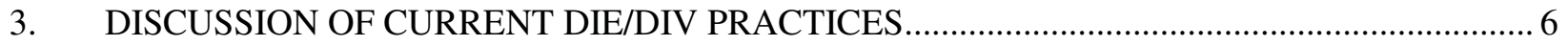

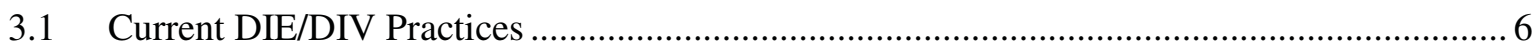

3.1.1 Verifying Facility Name and Location ................................................................... 6

3.1.2 Verifying Facility Size, Dimensions, and Manner of Construction ............................... 6

3.1.3 Verifying Main Process Areas and Absence of Undeclared Processing Space .......... 6

3.1.4 Verifying Essential Process Equipment - Components, Layout, and Configuration ............................................................................................... 7

3.1.5 Verifying Nuclear Material Flow Paths, Entries, Exits, Transfer Systems, and Key Measurement Points ............................................................................. 7

3.1.6 Verifying Nuclear Material Inventory, Hold-up, and Storage Areas, and

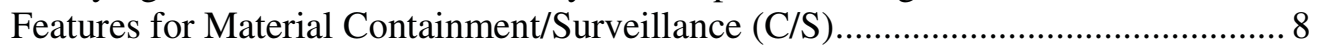

3.1.7 Verifying Planned or Installed Safeguards Instruments (Operator and

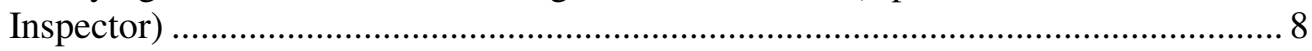

3.2 Examination of Facility Design Information and Preparing the DIV Plan ........................... 9

3.3 DIE/DIV Experience at the Rokkashomura Reprocessing Plant ........................................ 11

3.4 Periodic Re-verification of Design Information................................................................. 13

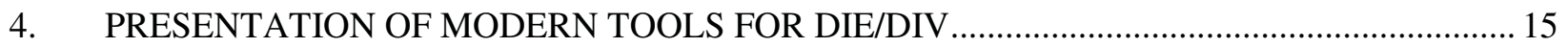

4.1 3-Dimensional Laser Range Finder (3DLR) ................................................................. 15

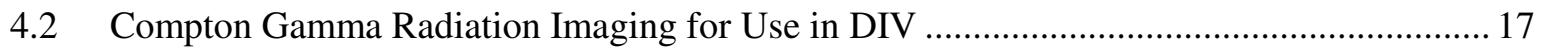

4.3 Laser Range Finder with Gamma Camera (Gamma-LIDAR) .......................................... 19

4.4 Enhanced Ground Penetrating Radar for DIV ............................................................. 21

4.5 Virtual Reality (VR) for DIV Reference Facility Models................................................... 22

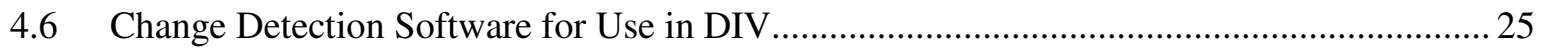

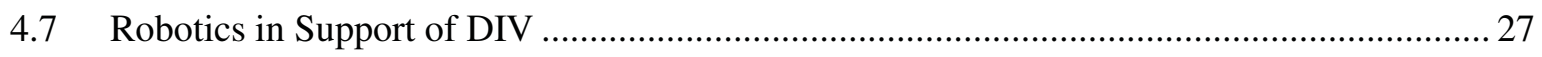

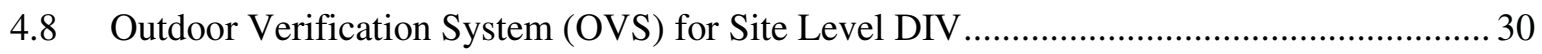

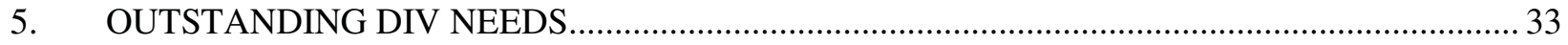

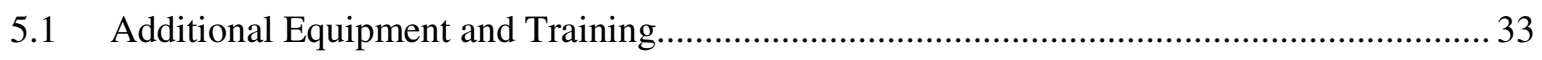

5.2 New and Improved Equipment and Associated Training …........................................... 33

5.3 Engineering Training for DIE/DIV (Blueprint Reading for Inspectors) ............................. 33 


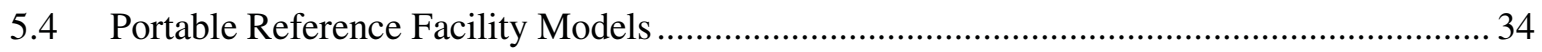

5.5 Automated Change Detection Tools ................................................................................ 34

5.6 Equipment for Detecting Concealed or Buried Nuclear Process Equipment........................ 34

5.7 Modern Methods for Storing, Handling, and Securing Design Information......................... 35

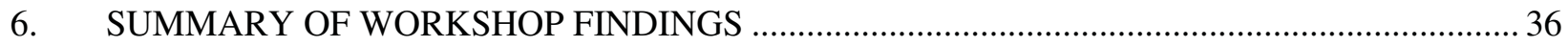

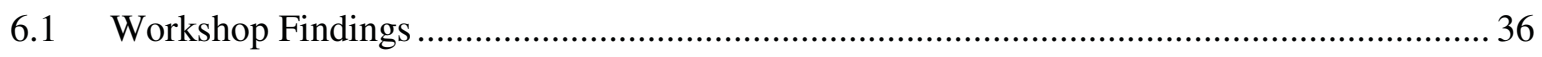

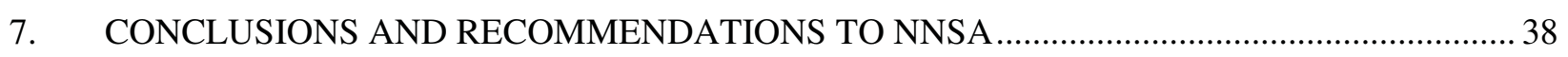

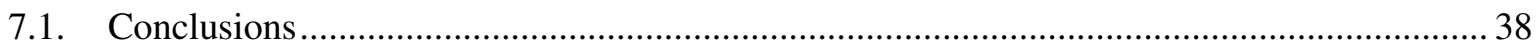

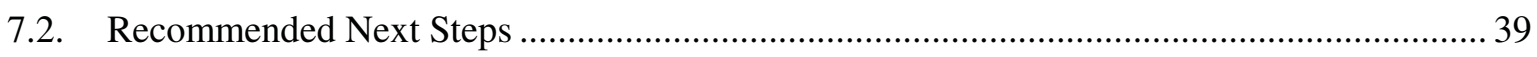

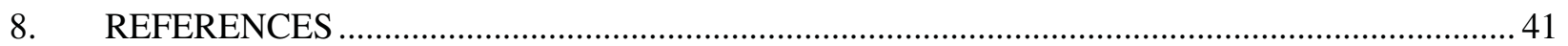




\section{FIGURES}

Figure 1: 3-Dimensional Laser Range Finder (3DLR) for DIV - Comparison of Mark-I (2003) and Mark-II (2008) Models.

Figure 2: 3DLR Automated Change Scene Detection Feature. (Areas changed prior to reverification are automatically highlighted in red.).

Figure 3: Compact Compton High Resolution Gamma Imaging Device. ................................................... 18

Figure 4: Compact Compton Imager Identifying Radioactive Hotspot..................................................... 18

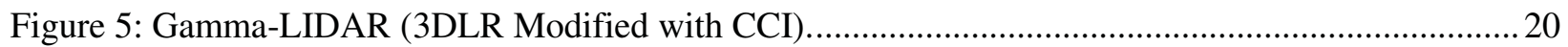

Figure 6: Gamma Radiation Map Produced by the Gamma-LIDAR ....................................................... 20

Figure 7: Virtual Model of Idaho Fuel Conditioning Facility (FCF) ..................................................23

Figure 8: Virtual Model of Hot Cell Operator Work Area. ..................................................................23

Figure 9: Comparison of Reference Photo for Enrichment Cascade Hall with Altered Image .................26

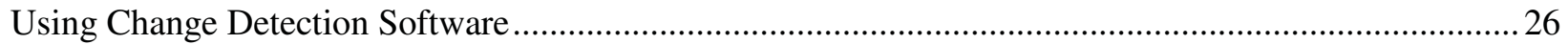

Figure 10: Miniature All Terrain Robotic Vehicle Developed for Hazardous Environment......................28

Figure 11: Comparison of the 3DLR (Left) and the OVS (Right)....................................................... 30

Figure 12: Scanning Route of the OVS for Surveying the Vienna International Centre (VIC).................31

Figure 13: 3-Dimensional Images of the VIC Using the OVS. ............................................................... 32

TABLES

Table 1: Number of Nuclear Facilities Under Safeguards or Containing Safeguarded Material.................5

Table 3: Compact Compton Imager (CCI) Pros and Cons. ...................................................................... 19

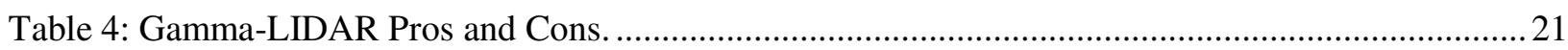

Table 5: Enhanced Ground Penetrating Radar (GPR) Pros and Cons. ....................................................22

Table 6: Virtual Reality (VR) Modeling for DIV Pros and Cons.........................................................25

Table 7: Planar Image Change Detection Software (CDS) Pros and Cons...............................................22

Table 9: Outdoor Verification System (OVS) Pros and Cons. ................................................................. 32 


\section{LIST OF ACRONYMS AND ABBREVIATIONS}

3DLR 3-Dimensional Laser Range Finder (Formerly 3DLRF)

AP

(IAEA) Additional Protocol (see also INFCIRC/540)

AREVA French/Multinational Company, Operator of UP-2/UP-3 Reprocessing Plants

ASA-100 (NA-243 Sponsored) Advanced Safeguards Approaches Project

BNFL British Nuclear Fuels Limited (Former Operator of THORP)

BNGSL British Nuclear Group Sellafield Limited (Formerly BNFL)

CCI Compact Compton Imager

CDS Change Detection Software

CIR (IAEA) Computerized Inspection Report

$\mathrm{C} / \mathrm{S} \quad$ Containment/Surveillance

CofK Continuity of Knowledge

COGEMA Former French Operator of UP-2/UP-3

COTS Commercial Off-the-Shelf

DA Destructive (Chemical) Analysis

DI Design Information

DIE Design Information Examination

DIV Design Information Verification

DIVP Design Information Verification Plan

DIQ Design Information Questionnaire

DOE U.S. Department of Energy

EC European Commission

EEL (IAEA) Essential Equipment List

EFL (U.S.) Eligible Facility List

ES Environmental (Swipe) Sample

EU European Union

Eu-152 Isotope of Europium

FCF (INL) Fuel Cycle Facility

FMEF Fuel and Materials Examination Facility

GCEP Gas Centrifuge Enrichment Plant

GPR Ground Penetrating Radar

GPS Global Positioning System

HCI Human Computer Interaction

HEU Highly Enriched Uranium 
INFCIRC/66 (IAEA) Early Safeguards Agreement (Limited to India, Israel and Pakistan)

INFCIRC/153 (IAEA) Model Comprehensive Safeguards Agreement

INFCIRC/540 (IAEA) Model Additional Protocol (AP)

INL (U.S. DOE) Idaho National Laboratory

ISBD Institutionalizing Safeguards by Design

JNFL Japan Nuclear Fuel Limited

JNSB Japan Nuclear Safety Bureau

JRC/Ispra Joint Research Centre of the European Commission in Ispra, Italy

JSGO Japan Safeguards Office

LANL (U.S. DOE) Los Alamos National Laboratory

LBNL (U.S. DOE) Lawrence Berkley National Laboratory

LEU Low Enriched Uranium

LFUA Limited Frequency Unannounced Access (to Enrichment Plant Cascade Halls)

LIDAR Light Detection and Ranging

LLNL (U.S. DOE) Lawrence Livermore National Laboratory

MOX Plutonium/Uranium Mixed Oxide

MUF Material Unaccounted For

NA-243 NNSA Office of International Regimes and Agreements

NDA Non-Destructive Analysis

NGSI (NNSA) Next Generation Safeguards Initiative

NNSA National Nuclear Security Administration

NPT Treaty on the Non-Proliferation of Nuclear Weapons

NRC U.S. Nuclear Regulatory Commission

NU Natural Uranium

NNWS Non-Nuclear Weapons State (NPT)

NWS Nuclear Weapons State (NPT)

ORNL (U.S. DOE) Oak Ridge National Laboratory

OVS Outdoor Verification System

PIV Physical Inventory Verification

PNNL (U.S. DOE) Pacific Northwest National Laboratory 


$\begin{array}{ll}\text { PP } & \text { Physical Protection } \\ \text { Pu } & \text { Plutonium, Chemical Symbol } \\ \text { QC } & \text { Quality Control } \\ \text { RRP } & \text { Rokkashomura Reprocessing Plant in Northern Japan } \\ \text { SBD } & \text { Safeguards by Design } \\ \text { SNL } & \text { (U.S. DOE) Sandia National Laboratory } \\ \text { SNRI } & \text { Short-Notice Random Inspection } \\ \text { SRNL } & \text { (U.S. DOE) Savannah River National Laboratory } \\ \text { SRS } & \text { (U.S. DOE) Savannah River Site } \\ \text { SQ } & \text { (IAEA) Significant Quantity } \\ \text { SSAC } & \text { State System of Accounting for and Control of Nuclear Material } \\ \text { Th } & \text { Thorium, Chemical Symbol } \\ \text { THORP } & \text { Thermal Oxide Reprocessing Plant (United Kingdom) } \\ \text { TRP } & \text { Tokai Reprocessing Plant, Tokaimura, Japan } \\ \text { U } & \text { Uranium, Chemical Symbol } \\ \text { U-235 } & \text { Fissile Isotope of Uranium } \\ \text { U-235\% } & \text { Uranium Enrichment Level (U-235 fraction as percent of total uranium) } \\ \text { UK } & \text { United Kingdom of Great Britain and Northern Ireland (also called United Kingdom) } \\ \text { UP-2/UP-3 } & \text { Reprocessing Plants at Cape de la Hague, France } \\ \text { USSP } & \text { U.S. Support Program to IAEA Safeguards } \\ \text { VIC } & \text { Vienna International Centre } \\ \text { VR } & \text { Virtual Reality } \\ \text { \$K } & \text { Thousands of US Dollars } \\ & \end{array}$




\section{Report of the Workshop on Nuclear Facility Design Information Examination and Verification For Safeguards}

\section{INTRODUCTION}

\subsection{Design Information Examination and Verification for Safeguards}

The International Atomic Energy Agency (IAEA) implements nuclear safeguards and verifies that countries are compliant with their international nuclear safeguards agreements. ${ }^{\mathrm{d}, 1}$ One of the key provisions in the safeguards agreement is the requirement for the country in question to provide nuclear facility design and operating information to the IAEA relevant to safeguarding the facility, and at a very early stage. ${ }^{\text {e, f, } 2,3}$ This provides the opportunity for the IAEA to verify the safeguards relevant features of the facility and to periodically ensure that those features have not changed. Design information for all facilities within a country is made available to the IAEA and includes:

1. Identification of the facility including general description, purpose, capacity, and location.

2. Description of the facility layout and nuclear material form, location, and flow.

3. Description of the features relating to nuclear material accounting, containment, and surveillance.

4. Description of the existing and proposed procedures of nuclear material accounting and control and definition of nuclear material balance areas.

This design information is declared by the facility operator through the national authorities (i.e. State System of Accounting for and Control of Nuclear Material or SSAC) to the IAEA using the Design Information Questionnaire (DIQ). It is updated as required by the SSAC via written addendum.

Design Information Examination (DIE) of declared information is carried out by IAEA Safeguards Inspectors to develop an effective safeguards approach for each facility. IAEA Safeguards Inspectors also perform a Design Information Verification (DIV) using this information, together with other available information, to confirm that the facility is built and used as declared. A DIV plan (DIVP) describing required verification activities, based on the stage in the facility's life-cycle, design features, and capacity,

\footnotetext{
${ }^{\mathrm{d}}$ In accordance with Article III.1 of the Treaty on the Non-Proliferation of Nuclear Weapons (NPT), non-nuclear weapons states are obligated to conclude a comprehensive safeguards agreement (CSA) that contains an, "an undertaking by the State to accept safeguards, in accordance with the terms of the Agreement on all source or special fissionable material in all peaceful nuclear activities within its territory, under its jurisdiction, or carried out under its control anywhere, for the exclusive purpose of verifying that such material is not diverted to nuclear weapons or other explosive devices." (Sources - IAEA INFCIRC/153 (corrected) and NPT)

${ }^{\mathrm{e}}$ According to a 1992 IAEA Board of Governors decision, all parties to comprehensive safeguards agreements are required to inform the IAEA of their programs for new nuclear facilities and activities as soon as the decision to construct the new facility has been taken. In April of 1992, "the Board called upon all parties to comprehensive safeguards agreements...to inform the Agency of their programmes for new nuclear facilities and activities, and for any modifications to existing facilities through the provision of preliminary design information, as soon as the decision to construct, to authorize construction, or modify has been taken." (Source - IAEA Board of Governors Report, GOV/2554/Attachment 2, April, 1992)

${ }^{\mathrm{f}}$ The provision of nuclear facility design information is required under both comprehensive safeguards agreements (INFCIRC/153-type) and INFCIRC/66-type agreements. Under an INFCIRC/66-type safeguards agreement, the State is to provide design information on principal nuclear facilities to enable the IAEA to perform the design review at as early stage as possible. (Sources - IAEA Safeguards Glossary, 2001 Edition, and INFCIRC/66, para. 31 and 32)
} 
is written and approved for each facility within a country. This plan is reviewed and implemented by the IAEA Facility Officer to ensure that an adequate DIE and DIV of the facility are performed. ${ }^{4,5}$

Design Information is defined by the IAEA in accordance with Reference 4 as follows:

"Design information is information concerning nuclear material subject to safeguards under the agreement and the features of facilities relevant to safeguarding such material. (INFCIRC/153, paragraph 8, similarly INFCIRC/66, paragraph 32). Design information includes the facility description and the form, quantity, location, and flow of nuclear material being used; facility layout and containment features; and procedures for nuclear material accountancy and control. This information is used by the IAEA... to design the facility safeguards approach, to determine the material balance areas, to select key measurement and other strategic points, to develop the Design Information Verification plan, and to establish the essential equipment list. Design information for existing facilities should be provided by the State during discussion of the Subsidiary Arrangements, and in the case of new facilities, such information is to be provided by the State as early as possible before nuclear material is introduced into a new facility. Further, the State is to provide preliminary information on any new facility as soon as the decision is taken to construct or authorize the construction of the facility, and to provide further information on the safeguards relevant features of the design early in the stages of project definition, preliminary design, construction, and commissioning. Facility design information is to be provided for any safeguards relevant changes in operating conditions throughout the facility life cycle. (Under an INFCIRC/66-type safeguards agreement, the State is to provide design information on principal nuclear facilities to enable the IAEA to perform the design review at as early a stage as possible.) Design information is submitted to the IAEA by the State using the IAEA DIQ."

The DIV activity is defined by the IAEA in accordance with Reference 4 as:

"Activities carried out by the IAEA at a facility to verify the correctness and completeness of the design information provided by the State. An initial DIV is performed on a newly built facility to confirm that the as-built facility is as declared. A DIV is performed periodically on existing facilities to confirm the continued validity of the design information and of the safeguards approach. The IAEA's authority for performing a DIV is a continuing right throughout all phases of a facility's life cycle until the facility has been decommissioned for safeguards purposes."

The DIVP is defined by the IAEA in accordance with Reference 4 as:

"A document prepared by the IAEA identifying the Design Information Verification activities required for each phase of a facility's life cycle."

Relevant to the DIE/DIV activity is the Essential Equipment List (EEL), which is defined by the IAEA in accordance with Reference 4 as:

“...A list of equipment, systems, and structures essential for the declared operation of a facility. The EEL is facility specific and is established during DIE. It identifies those items that may influence the facility's operational status, function, capabilities, and (nuclear material) inventory. The list is maintained and updated as part of the DIVP implementation." 


\subsection{Purpose of the DIE/DIV Technical Workshop}

Under the Next Generation Safeguards Initiative (NGSI), the National Nuclear Security Administrations (NNSA) Office of NA-24 identified the need for more effective and efficient verification of design information by the IAEA as an "Enabling Technology Need" in support of international safeguards. ${ }^{6}$ This becomes more important and urgent as larger and complex nuclear facilities are designed, constructed, and put into operation. For this reason, the NNSA Office of International Regimes and Agreements (NA 243) sponsored a group of U.S. Department of Energy National Laboratory nuclear safeguards experts and technologists to conduct a workshop on methods and technologies for improving this activity, under the ASA-100 Advanced Safeguards Approaches Project. The purpose of the workshop was to review and discuss how nuclear facility design information is currently examined and verified by the IAEA, consider advanced tools and methods that could improve the efficiency and effectiveness of this activity, and make recommendations to NNSA for improving this activity in accordance with the Next Generation Safeguards Initiative. 


\section{REVIEW OF CURRENT DIE/DIV SAFEGUARDS NEEDS}

The primary objective of the DIE/DIV activity is to verify from a nuclear safeguards perspective that the facility is constructed and operated as declared, and has not been changed or modified without notice. In simplest terms, the IAEA safeguards inspector must verify that the facility location, purpose, function, size, and capacity for handling, processing, and storing uranium, plutonium, and thorium are as declared. As noted in more detail in Reference 4, design information includes:

"the facility description; the form, quantity, location, and flow of nuclear material being used; facility layout and containment features; and procedures for nuclear material accountancy and control. This information is used by the IAEA, inter alia: to design the facility safeguards approach, to determine the material balance areas, to select key measurement and other strategic points, to develop the Design Information Verification plan, and to establish the essential equipment list."

Consequently, there is a nuclear safeguards need to verify the:

1. Facility name and location.

2. Facility size, dimensions, and manner of construction to accurately confirm the overall facility size and gauge facility capacity.

3. Process size and absence of undeclared process space, including basements, sub-basements, and pipe trenches, to confirm the overall size of the process, to estimate process capacity, and to inspect potentially concealed areas.

4. Size, number, list, and configuration of essential process equipment, vessels, and piping to confirm size and process capacity and better determine nuclear material flow key measurement and other strategic points.

5. Nuclear material flow paths, entries and exits, manner of conveyance or transfer, and measurement points to confirm nuclear material pathway, possible diversion paths, and establish flow key measurement points and other strategic points.

6. Areas for storing and containing nuclear material, and equipment for measuring, monitoring, sealing, and surveilling nuclear material inventory, and to establish inventory key measurement points for such nuclear material

7. Installed or planned safeguards instruments, for both the operator and the inspector, to verify that the points or containers measured and associated safeguards data will meet the needs for nuclear material accounting. This includes an assessment of the instrument accuracy, measurement frequency, and data collection and transmission security.

According to the IAEA Annual Report for 2007, the IAEA implements safeguards and conducts inspections at 949 nuclear facilities, in both non-nuclear weapon and nuclear weapons states. Of these, we estimate that approximately 30 are currently under construction or are undergoing start-up. The facilities that are subject to regular or routine inspection will normally be subject to one physical inventory verification per year, which is typically when the design information is periodically re-verified.

A breakdown of the number and types of nuclear facilities that are regularly subjected to routine IAEA safeguards inspection and design verification are listed in Table $1 .{ }^{7}$ 
Table 1: Number of Nuclear Facilities Under Safeguards or Containing Safeguarded Material (Source - IAEA Annual Report for 2007)

\begin{tabular}{|l|c|}
\hline $\begin{array}{l}\text { Nuclear Power Plants } \\
\text { (Including On-Load Refueled Reactors, [i.e., CANDU, and Fast Breeder Reactors]) }\end{array}$ & 197 \\
\hline Research Reactors and Critical Assemblies & 142 \\
\hline Uranium Conversion Plants & 18 \\
\hline Uranium Enrichment Plants & 14 \\
\hline $\begin{array}{l}\text { Fuel Fabrication Plants } \\
\text { (Including HEU and MOX Fabrication) }\end{array}$ & 39 \\
\hline Spent Fuel Reprocessing Plants & 8 \\
\hline $\begin{array}{l}\text { Separate Storage Facilities } \\
\text { Including Away from Reactor Spent Fuel Storage) }\end{array}$ & 98 \\
\hline Other Facilities & 65 \\
\hline Other Locations & 368 \\
\hline Total & $\mathbf{9 4 9}$ \\
\hline
\end{tabular}

As can be seen in the above table, a very large number of nuclear facilities worldwide are regularly subject to IAEA safeguards inspection and Design Information Examination and Verification. It is also important to note that the total number of facilities is constantly growing, and the types of facilities are becoming more complex and strategically important - i.e. uranium enrichment, spent fuel reprocessing, and MOX fuel fabrication plants. As a consequence, there is a growing need for experienced and trained safeguards inspectors and methods and techniques for performing DIE/DIV efficiently especially at these facilities. This was demonstrated at the extensive DIE/DIV at the Rokkashomura Reprocessing Plant (RRP) in northern Japan, and is one of the main motivations for this workshop - to discuss and present current safeguards needs in this area and to review advanced technology that could help address those needs. More will be said about this in Section-3.3, "DIE and DIV Experience at the Rokkashomura Reprocessing Plant." 


\section{DISCUSSION OF CURRENT DIE/DIV PRACTICES}

\subsection{Current DIE/DIV Practices}

In addressing the current DIE/DIV practices used by the IAEA, we refer to the safeguards verification needs as noted in the previous section. Many of the attendees at the workshop were former IAEA safeguards inspectors, or had participated in DIE/DIV activities in support of the IAEA. The following discussion of current practices is based on their first-hand experience. It should also be noted that the following is a general summary of current practices performed by IAEA safeguards inspectors for performing DIE/DIV. These activities should not be considered as all inclusive, since large and complex facilities may require special considerations depending on facility specific features or construction. However, the discussion of current practices, together with the defined safeguards needs, established a point of reference for the ensuing discussions at the Workshop. The DIE and DIV activity are performed in accordance with the IAEA Safeguards Manual, Part SMI, Chapter SMI 4.1. ${ }^{8}$

\subsubsection{Verifying Facility Name and Location}

To verify the name and location of the facility, the safeguards inspector typically uses the facility name, address, and map as provided in the IAEA DIQ and compares this with what is observed at the actual location identified during the DIE/DIV activity or routine inspection. Equipment is also now available that allows the inspector to use the Global Positioning System (GPS) to confirm the local coordinates for the facility. Open-source information, including magazine articles and facility brochures, can help corroborate the facility location. In some cases, the IAEA provides overhead satellite imagery to verify that the location is correct as declared.

\subsubsection{Verifying Facility Size, Dimensions, and Manner of Construction}

IAEA inspectors typically use hand tools, such as construction tape-measures and laser distance instruments, to verify the external footprint and dimensions of nuclear facilities. The inspector compares the measured and observed facility dimensions and features against the information declared in the DIQ and on the facility plot plans, plan views, construction drawings, and photographs as provided by the plant operator through national authorities. For very large structures, GPS coordinates can also be taken and converted to vertical and horizontal dimensions if the inspector has access to the perimeter and upper deck or roof of the facility. The facility footprint is often compared against other similar facilities in order to estimate the overall size, processing and storage capacity of the facility. This is only a rough estimate for this purpose, but it is useful when combined with other observations. The site boundary and site layout is typically verified while the facility is under construction; otherwise, this activity becomes a greater challenge to perform retroactively.

\subsubsection{Verifying Main Process Areas and Absence of Undeclared Processing Space}

IAEA inspectors typically use the same tools and techniques for verifying dimensions and layout of main process areas of site buildings, as they would when verifying building exteriors. The 3DLR, developed by JRC/Ispra, is a laser-based survey tool that has been developed for comparing actual construction against original design drawings. It has been used very effectively by the IAEA to perform DIV at the Rokkashomura Reprocessing Plant (RRP) in Japan and at selected facilities in Europe. More will be said about this tool and its use in Section 3.3 and in Section 4.

To aid in the verification of the process area, the IAEA inspector uses the declared information in the DIQ, as well as process schematics, layout drawings, and photographs provided by the plant operator through the SSAC. It is essential that this information be current, since the facility operator can expand the processing or storage capacity of the facility, sometimes at very short notice. These changes need to 
be declared to the IAEA in advance of taking place, as noted in the safeguards agreement between the country and the IAEA. During the verification of the process area, the inspector pays close attention to any interconnecting hallways, doorways, access points, pipe trenches, basements, sub-basements, mezzanines, and upper decks that could permit undeclared extension of the main process area.

\subsubsection{Verifying Essential Process Equipment - Components, Layout, and Configuration}

Inspectors use visual observation, together with the declared information in the DIQ and operatorprovided process equipment layout, equipment fabrication, and installation drawings and photographs to verify the number, size, and configuration of essential process equipment. Inspectors have also used the 3DLR for this purpose, which is especially well suited for documenting the actual construction. The 3 -dimensional scan of the area recorded by the 3DLR includes details of process vessels and interconnecting piping, ductwork, and tubing scanned. Later the inspector can compare this against previous scans recorded by the 3DLR to automatically detect changes. The inspector can also take dimensions directly off the scanned 3-dimensional image to determine the external dimensions of vessels, pipes, etc. This allows the inspector to quickly estimate the size and capacity of most types of process vessels, at least those that can be evaluated externally.

However, the inspector must still compare this computerized 3DLR scanned image against the operator's declaration to verify that the process equipment has not been modified and is as declared. From the operator's declaration and the initial DIE/DIV, the inspectors will compile the EEL, which will aid in determining the capacity of the process or handling area, and be used as a benchmark from which to gauge changes in the future. If the 3DLR is not available, a team of inspectors carefully inspect the main process areas using hand-held tools and design drawings. For a sensitive facility, such as an enrichment plant, a MOX fuel fabrication plant, or a spent fuel reprocessing plant, this normally requires a number of DIE/DIV activities per year during the construction of the facility, which may take up to ten years or more to complete.

\subsubsection{Verifying Nuclear Material Flow Paths, Entries, Exits, Transfer Systems, and Key Measurement Points}

Inspectors observe the declared nuclear material flow paths, entries, exits, and transfer systems, and determine the location of the flow key measurement points (KMP). They also consider the placement of radiation detection, monitoring, and assay equipment for verifying the nuclear material that will transfer across these key measurement points. IAEA inspectors have also used the 3DLR to support this activity, especially for verifying doors, hatch-ways, installed piping, ducts, and conveyor systems. The 3DLR is very effective for recording precise dimensions, configuration, and installation details in this regard. However, for the most part, this activity remains one largely based on inspector visual observation and established practices.

The placement of key measurement points, and the instruments to monitor nuclear material flow, is often based on experience with similar facilities. Flow verification, however, has become more challenging in large and complex spent fuel reprocessing and MOX fuel fabrication plants because of sensitivity to the placement and accuracy of the assay systems. In order to meet the IAEA's primary safeguards goal of the timely detection of the diversion of one significant quantity (SQ) of nuclear material, ${ }^{\mathrm{g}}$ the installation of more assay instruments and more accurate instruments is required. These are

\footnotetext{
g. A Significant Quantity (SQ) of nuclear material is a term used by the IAEA and is approximately the amount of fissile nuclear material required to fabricate an atom bomb. One SQ of plutonium is $8 \mathrm{~kg}$. The safeguards goal becomes the detection of the diversion of $8 \mathrm{~kg}$ of plutonium (with a confidence level of $95 \%$ ) within the timeliness goal for detection of one month for plutonium handling facilities. (Source - IAEA Safeguards Glossary - 2001 Edition)
} 
necessary to cover all nuclear material transfer points, including the process feed, process output, and numerous scrap recycle, high-level (highly radioactive), medium-level, and low-level waste streams in these more complex facilities.

\subsubsection{Verifying Nuclear Material Inventory, Hold-up, and Storage Areas, and Features for Material Containment/Surveillance (C/S)}

The methods used in verifying nuclear material flow paths are similarly used to verify the locations and construction features where nuclear material will accumulate as hold-up, be inventoried, or stored. In the simplest case, the nuclear material storage area is a ruggedized vault with standardized security and physical protection features. While these features are very important for the total safeguards, security, and physical protection of the nuclear facility, the safeguards inspector evaluates those features directly affecting the containment of nuclear material and possible undeclared removal of nuclear material. The inspectors survey and measure the storage area and planned inventory locations to determine if the proposed containment area and features will be effective. Inspectors consider the installation of purpose-built tamper indicating devices, including electronic and manual sealing systems, video surveillance, and radiation monitors for detecting the undeclared removal of nuclear material. Inspectors also consider the placement and design of unattended assay monitoring systems for inventorying nuclear material transferred to storage, which becomes especially challenging in the case of modern spent fuel reprocessing and MOX fuel fabrication facilities, because of the need to make very precise nuclear material measurements for plutonium content at numerous inventory and flow key measurement points.

\subsubsection{Verifying Planned or Installed Safeguards Instruments (Operator and Inspector)}

Typically, inspectors plan the placement of safeguards surveillance and instrumentation while examining the declared design information. However, the construction of a modern complex nuclear facility occurs in methodically orchestrated stages, and it is not always clear to the safeguards inspector how the complete safeguards system will appear in final form, or how all the safeguards verification measures will ultimately integrate. The systematic approach of establishing proper containment and surveillance is governed by site surveys performed by a joint team of multi-discipline experts.

Safeguards inspectors and technical support groups work together and coordinate with the facility operator and national authorities to plan, design and install appropriate containment and surveillance measures, typically during the pre-construction stage. More detailed surveys and actual equipment installation occurs during nuclear facility construction. It is very challenging for safeguards inspectors to consider the interconnection and interaction with complex safeguards components and systems for large, complex, and strategically important facilities, such as enrichment, reprocessing, and MOX fabrication plants. When construction is completed, the inspectors review all of the systems together and determine if the installed safeguards measures are complete and if they can be defeated or circumvented.

Inspectors also perform or observe extensive calibrations of installed safeguards instruments, including bulk volume and mass measuring systems to verify that they are: i) properly installed, ii) will provide the necessary accuracy, and iii) will cover the materials and process streams of safeguards interest. Special attention is given to safeguard data collection, integration, and transmission to ensure that as the safeguards systems are interconnected, they will perform the intended safeguards function effectively and securely.

While these activities are most effectively done prior to facility start-up, or introduction of radioactive material into the facility, inspectors continue to perform these verification activities during DIE/DIV's over the operating life of the facility through plant shutdown and decommissioning. More will be said on this later in Section 3.4, "Periodic Re-Verification of Design Information." 


\subsection{Examination of Facility Design Information and Preparing the DIV Plan}

During the Design Information Examination (DIE), the inspector reviews and compares design and operating information declared by the facility operator in the DIQ, and all other information available to the IAEA - i.e. engineering design drawings, sketches, test data, photographs, and magazine articles. The IAEA Facility or Site Officer is responsible for planning, organizing and performing the examination and re-examination of the safeguards relevant design and operating information throughout the life-cycle of the facility. ${ }^{\mathrm{h}}$ The design information (DI) is examined for developing and implementing the facility safeguards approach. The operator's declaration is examined for correctness, completeness, consistency, and timeliness of the DIQ provided to the IAEA. Relevant descriptive and technical information should be provided in the document, which would support the development and implementation of a safeguards approach.

In developing safeguards approaches, inspectors rely on model approaches developed within the IAEA for similar facilities, although larger and more complex facilities or facilities of unique construction may require the development of a unique or customized safeguards approach. Facility specific safeguards approaches are based on the declared design information, which is examined for the installation of effective containment and surveillance (C/S) measures. The SSAC conveys design information in the form of the DIQ for all new and existing facilities, which is examined by the Facility Officer. Any questions, translations, or clarifications that an inspector may have are sent back to the facility operator through official channels to the SSAC. Once the DIQ has been submitted, an initial DIE/DIV is usually performed during the construction and commissioning phases for newly built facilities.

According to the IAEA Safeguards Manual, DIE/DIV is performed in order to: ${ }^{9}$

a) "Confirm the correctness and completeness of the design information;

b) Obtain additional design and/or design-related information through visual and technical measures, and through discussion with the State and facility operator;

c) Systematically confirm the as-built design features of the facility which are relevant to IAEA safeguards;

d) Contribute to the design implementation and evaluation of the (facility) safeguards approach;

e) Provide assurance that the facility has been designed for its declared purpose, identify potential misuses of the facility, and that no undeclared activities can take place;

f) Identify sensitive design related information, documents, and records that must be kept on-site and under C/S for future examination and verification of design information."

The IAEA Facility or Site Officers prepare the Design Information Verification Plan (DIVP), outlining the objectives and arrangements for conducting the Design Information Examination and verification during each phase of the facility's life-cycle. DIVPs specify the i) methods for Design Information Verification, ii) documentation requirements; iii) requirements for securing the information, and iv) detailed procedures for specific DIV activities. Preparation of the initial DIVP is often done in conjunction with the initial Design Information Examination to determine relevant verification objectives for the facility at each stage of its life-cycle. The DIVP is separated into several parts: status, description, objectives, activities, notes, attachments, and approvals. Each section is relevant to the planning of a successful DIE/DIV.

h. IAEA Safeguards Manual, SMI 4.1. 
As per the IAEA Safeguards Manual, the phases of the facility life-cycle are defined as follows:

a) "Pre-Construction

b) Construction

c) Commissioning

d) Operating

e) Maintenance/Modification

f) Shut-down

g) Closed-down, (i) State of Preservation and (ii) State of Decommissioning

h) Decommissioned for Safeguards Purposes."

Facility DIVPs provide inspectors with facility status, description, and DIE/DIV objectives. Typical verification activities specified during a DIE/DIV are summarized in the list below, as per the IAEA Safeguards Manual: ${ }^{\mathrm{i}}$

“ED—General examination of design information

GD_Examination/verification of siting and general building design

$C D$-Examination/verification of process and/or containment design

$U D$ Examination/verification of utility/support design

EE_Examination/verification of essential equipment

$M F-E x a m i n a t i o n / v e r i f i c a t i o n$ of nuclear material flow design

$M L-E x a m i n a t i o n / v e r i f i c a t i o n$ of nuclear material location design

$N M$-Examination/verification of nuclear material characteristics

CS_Examination/verification of containment integrity (penetrations)

OM-Verification of operator's measurement system

$O P$-Examination/verification of operating procedures

OR_Examination/verification of operating records

$A P$-Examination/verification of accountancy procedures

AR-Examination/verification of accountancy records

OS-Verification of operational status (detection of undeclared operations)

SG-Assessment of validity of safeguards approach”

Once prepared and examined by the Facility Officer, the DIVP is added to an IAEA inspection package for briefing the inspectors who will perform the activity. As new technology becomes available, the DIVP is reviewed to make sure that it is still current. Potential improvements to the DIVP are regularly fed back to the Facility Officer by the inspectors performing the activity to help keep the Design Information Verification Plan current and efficient. In preparing the DIVP, due consideration is given by the inspectors to reducing interferences to the nuclear facility operator and their activities.

\footnotetext{
${ }^{\mathrm{i}}$ The IAEA verification and activity codes noted above are as per the IAEA Safeguards Manual, Section SMI-4.1.
} 


\subsection{DIE/DIV Experience at the Rokkashomura Reprocessing Plant}

The Rokkasho Reprocessing Plant (RRP) in northern Japan is the only large-scale commercial reprocessing plant completely under IAEA safeguards, from the head-end to MOX conversion and storage. Since the IAEA's efforts were so extensive for such a large facility, and because the IAEA was involved in DIE/DIV activities at the earliest stage of conceptual design, the international experience at this facility will be recounted as an example of what may be expected as larger and more complex fuel cycle facilities are placed under international safeguards. ${ }^{10}$ While important lessons can be learned from this activity, it should also be remembered that these lessons are more relevant to large and complex nuclear-chemical processing facilities, such as reprocessing plants, enrichment plants, and MOXconversion and fuel fabrication plants. Although some of these lessons can be applied to nuclear power plants, research reactors, and other smaller and less sensitive nuclear facilities, the scale and scope of DIE and DIV activities will necessarily be less for the smaller facilities that do not handle or produce fissile nuclear material.

Japan Nuclear Fuel Limited (JNFL) began considering the construction of a commercial large-scale spent fuel reprocessing plant in Japan in the late 1980s. At that time, the Tokai Reprocessing Plant (TRP), which had been operating in the village of Tokaimura since 1977, could not reprocess all of the spent fuel discharged from nuclear power plants in Japan. The excess spent fuel was reprocessed at the Thermal Oxide Reprocessing Plant (THORP) in the United Kingdom and at the UP-2 and UP-3 spent fuel reprocessing plants in Cape de la Hague, France, operated by COGEMA. Because of the need for additional domestic reprocessing capacity, JNFL designed a large-scale state-of-the-art commercial reprocessing plant to be sited in northern Japan in Aomori Prefecture, near the village of Rokkashomura. While discussions between JNFL and the IAEA began in the late 1980s regarding the intention to construct this plant, review of the initial design drawings and design information did not begin until the mid 1990s. At that time, the examination and review of the design drawings was performed by IAEA inspectors at the JNFL business office in Tokyo. The drawings and safeguards relevant process schematics and flow-sheets were kept on a secured computer in a protective enclosure, which was sealed by both Japanese national authorities (the then Japan Nuclear Safety Bureau - JNSB) and the IAEA. During these initial stages, the examination of the design information and design drawings focused on consistency regarding the declared function and capacity of the reprocessing plant. However, even at this initial stage, inspectors paid attention to potential nuclear material removal pathways and the prospective location for safeguards C/S devices-especially in the spent fuel pond and head-end area of the plant.

In 1996, ground-broke for construction and the DIE/DIV activities moved north from Tokyo to the JNFL construction site near the village of Rokkashomura. At this stage, IAEA inspectors examined the level of the excavations in preparation for the pouring of the extensive and elaborate multiple basement levels. Many of the process buildings have as many as four basement levels. IAEA inspectors needed to confirm the absence of undeclared processing or nuclear material storage areas, so they followed the construction process closely. Initially, DIE/DIV activities were scheduled approximately once every three months. Later, as the construction of the process areas progressed to the installation of process piping and vessels, the frequency of this activity became monthly. A key factor in making this process efficient was the creation of an IAEA Safeguards Coordination Team within JNFL with a responsible manager, and the staffing of a cost-free expert from JNFL at IAEA Headquarters in Vienna, to facilitate communication with the IAEA — especially regarding construction status and site readiness for performing DIE/DIV activities. From 1996 through 2002, IAEA inspectors conducted DIE/DIV using traditional tools: construction tape measures and rulers, laser distance meters, Polaroid cameras, sketch pads, etc. These were reasonably effective during the early stages of construction, since the focus was on the larger architectural features of the facility, with attention being paid to nuclear material flow paths and potential removal routes. 
During this period, the European Commission's Joint Research Centre (JRC) in Ispra, Italy, had been working with the IAEA in Vienna on developing a tool to make the DIV activity more systematic and efficient. This led to the development of the 3-Dimensional Laser Range Finder (3DLR). This was an engineering survey tool that used an infrared laser, which scanned radially and axially to produce a threedimensional computer generated map of a room or process cell, based on the time correlated reflection of the laser beam. The 3DLR was used inside the building and process cells and had an initial range of 50 meters, which later increased to $80 \mathrm{~m}$. However, the laser was blocked by solid objects, so the device had to be positioned in several corners of cells that were densely packed with process vessels and piping. More will be said about the 3DLR in Section 4, "Presentation of Modern Tools for DIE/DIV." The benefit of the 3DLR is that it allowed trained inspectors the ability to rapidly survey and verify the construction of very complex process cells-far beyond the fidelity of hand measurements and sketching. It was however, still useful to make a record and sketch of where the scanning had been performed, since inspectors would later need these notes to merge the multiple scans that had been collected in complex process cells and areas.

From 2002 onward, the 3DLR became an invaluable tool at RRP. During this period, there were some issues with the equipment, which will be described in further detail in Section 4. However, these issues were resolved in the redesign of the system with the production of the Mark-II (2008) Model. In addition to the highly faithful rendering and computer modeling of scanned process cells and equipment, the scans could be checked back in the inspectors' on-site office on a computer workstation for dimensions and consistency against design drawings. The field verification activity now focused more on data collection, using the 3DLR, with comparison of the design information for consistency in the inspectors' office.

Most IAEA inspectors that used the 3DLR were very impressed that such a sophisticated tool had been provided to support the extensive and otherwise time-consuming DIE/DIV activities. However, the 3DLR did have certain reasonable limitations and inspectors still needed to be mindful of what these were. While the 3DLR could capture design and installation details to the level of high-resolution photogrametry $( \pm 1 \mathrm{~mm})$, inspectors still needed to review the scanned images and manually compare with the design drawings to confirm the consistency of safeguards relevant features-such as process vessel external dimensions and piping connections and routes. However, the 3DLR did employ change detection software (CDS) internally and could be used on subsequent occasions to verify whether major changes had been made to a scanned area. As an infrared laser-based system, the 3DLR was less effective in very tightly packed process cells. Even if the scanned images were partly incomplete, because the beam had been blocked, this was still more detailed information than anything the inspector could capture by observation and drawing. Coordinating the timing of when to scan the cell using the 3DLR became significant. With around-the-clock construction activities at RRP, it was not uncommon that process cells still contained extensive scaffolding and tarpaulins that blocked the view of the 3DLR. Nonetheless, communication with the JNFL Safeguards Coordination Team was generally excellent and was a model for future IAEA DIE/DIV activities.

The merging of multiple scans, especially in very elaborate process cells, took considerable time in the inspector's office on site. This activity was not as trivial as first expected, since the scanned view was dependent on the location where the 3DLR was placed. If inspectors had not noted this carefully on a working paper during the scanning process, then it was very difficult to interpret the scan and merge the images to make a complete computerized model of the process cell. The inspectors also needed to be able to read and understand the variety of engineering blueprints: electrical, mechanical, architecture/structural, instrumentation, process piping, and process vessel fabrication drawings. Many IAEA inspectors did not have this engineering training. This became a prerequisite for using the 3DLR and comparing the scanned images to the various design drawings.

Another significant issue that arose was the proper storing and control of the inspector generated facility information. Locked file cabinets were used to store the facility operator's design drawings and 
other safeguards relevant design information, under joint seal in the inspectors' office at the facility. However, the 3DLR generated nearly-photographic quality images that captured proprietary and safeguards sensitive design details. The national authorities and facility operator were watchful that IAEA inspectors did not remove a hard disk from the resident 3DLR workstation with scanned data for review back in Vienna. All of the safeguards relevant DIE/DIV activity was performed in the inspectors' office on site at the facility. Control of this data is still a very important and sensitive issue that potentially limits the broader application of the 3DLR to other locations.

This section was a quick summary of the recent DIE/DIV activities in support of international nuclear safeguards at the modern RRP facility. It does not discuss all details, but it does focus on the major points and evolution of the necessary tools. From this experience, it can be deduced that the 3DLR was a highly effective tool and should be used more broadly than it currently is. More will be said about this later in this report. Another point to bear in mind is that the 3DLR, as currently configured, cannot be used in inaccessible high-radiation areas, and cannot peer into poured concrete walls, floors, or soil to detect concealed process piping or vessels. These prospective safeguards needs are discussed later in this report, regarding the Compact Compton Imager (CCI) and enhanced Ground Penetrating Radar (GPR).

While the 3DLR was very effective at verifying external dimensions and process vessel and piping configurations, it could not verify internal vessel features, which was still done by visual observation with the aid of cameras and sketch pads. Additionally, the IAEA observed extensive process vessel calibrations of the solution level (volume) and density instruments during the commissioning and startup of the process and facility. This remains a very important DIE/DIV activity that was not addressed by the 3DLR and is a very complex and time-consuming safeguards activity. This activity also requires the support of highly trained and experienced process engineers to faithfully monitor the operator's process vessel calibration activity. Once these initial calibration curves are generated, it is difficult to access the process vessels after the facility goes hot. Annual re-calibrations of these safeguards relevant instruments are performed, but the initial calibrations are the foundation for the future and the most important, in terms of safeguards.

\subsection{Periodic Re-verification of Design Information}

In accordance with the IAEA's Model Comprehensive Safeguards Agreement, INFCIRC/153 (corrected), regarding the re-examination and re-verification of facility design information, it states the following: ${ }^{11}$

"The (Safeguards) Agreement should provide that design information shall be re-examined in the light of changes in operating conditions, of developments in safeguards technology, or of experience in the application of verification procedures..."

The IAEA meets this requirement by periodically re-examining and re-verifying facility design information at least once per year, typically at the time of the annual Physical Inventory Verification (PIV). Re-verification occurs throughout the life of the facility, and may be triggered when: i) Change in the facility life-cycle; ii) Modifications are made that change the nominal capacity; and iii) As agreed in IAEA Facility Subsidiary Arrangements. Re-verification of existing facilities is very important to confirm that the safeguards approach remains valid and that safeguards relevant changes have been made.

Regarding periodic re-verification of design information, the IAEA Safeguards Manual states:

"DIV is performed periodically on a continuing basis at existing facilities under safeguards that have previously hand an initial DIV. A periodic DIV is not a complete verification, but contributes to the cumulative knowledge of the facility design, its operation, the continued validity of the safeguards approach, and evaluation of resource requirements. Periodic DIVs are performed throughout the lifetime of the facility according to the frequency 
specified in the (IAEA) Safeguards Criteria or in the relevant DIVP. For an operating facility, the periodic DIV should, if possible, be performed in conjunction with routine inspections (either during IIV or PIV).

In planning a periodic DIV, a limited number of the objectives defined in the DIVP should be selected."

The activities previously described for the DIE and DIV and preparation of the Design Information Verification Plan (DIVP) are still relevant for the re-verification activity. As per the IAEA Safeguards Manual, the activities include the following:

a) "Confirm that the design information continues to be correct and complete;

b) Obtain additional design and/or design-related information through visual and technical measures and through discussions with the State and facility operator;

c) Re-confirm the as-built design features of the facility, which are relevant to IAEA safeguards;

d) Evaluate if the safeguards approach continues to be appropriate, taking into consideration the facility design, capabilities, and available verification methods;

e) Provide assurance that there are no undeclared modifications to the facility, or there is no misuse of the facility;

f) Confirm that the operational status is as declared;

g) Confirm that the facility's design-related information, documents and records, kept on site and under $C / S$, continue to be appropriate and adequate;

h) Resolve possible discrepancies and anomalies;

i) Address current safeguards issues."

The IAEA Safeguards Manual goes on further to say that the frequency of periodic DIV (reverification) should take into consideration the following:

a) "The results of the re-examination of the design information;

b) The type, operating capacity, capabilities, and facility life-cycle phase;

c) The status of the essential equipment in the facility;

d) The category and quantity of nuclear material present at the facility."

The point of the foregoing discussion is to underscore that the DIE/DIV activity continues over the various phases and stages of the facility through its life-cycle. While these safeguards verification activities may not be as comprehensive as during the initial construction of the facility, they are still essential to confirm that the facility safeguards approach remains valid and the facility has not been altered in a safeguards-relevant manner. 


\section{PRESENTATION OF MODERN TOOLS FOR DIE/DIV}

The following section summarizes the key presentations made at the Workshop, which covers modern and advanced technologies capable of addressing the current DIE/DIV needs as noted in Section 2. To introduce the relevant technology, each section is introduced by the need in bold.

\subsection{3-Dimensional Laser Range Finder (3DLR)}

\section{There is a need to verify the safeguards relevant features of complex nuclear material processing areas and cells.}

The 3DLR is a modern laser based survey tool made by Zoller and Froehlich GmbH adapted for DIV by the European Commission's Joint Research Centre (JRC) in Ispra, Italy and is shown in Figure $1 .^{12}$

The system emits a rapidly rastered infrared laser beam that rotates axially and radially to produce a laser emission in a spherical shell. The reflected laser beam points are collected by a receiver and the reflected beams are interpreted for distance and the data stored. A portable laptop computer compiles and integrates the data, producing a three dimensional image that can represent dimensions on the order of $\pm 1 \mathrm{~mm}$. The instrument can produce a high-resolution 3-dimensional computerized image of the area surveyed in typically less than five minutes. This tool has been so effective in capturing the configuration of installed equipment and newly built facilities that it is becoming more commonly used for post-construction quality control (QC) verification by design constructors and QC organizations, in lieu of photogrammetric methods. This technique has been used extensively by the IAEA in the DIE/DIV of the RRP as described in Section 3 of this report. The main limitation of this instrument is the laser beam range of 50 to 80 meters, which can be addressed by taking multiple scans at step-wise increments to cover a longer distance. Since the infrared laser is blocked by solid objects, it is also necessary to take multiple scans when scanning or surveying a process area or cell with densely packed vessels and/or piping. The IAEA's experience with this device has been favorable and is described in Sequeira et al. ${ }^{13}$ After the inspector collects an initial scan for a reference image, the inspector can return at a later date and re-scan the area for re-verification. The 3DLR system has built-in Change Detection Software (CDS) that will highlight areas that have changed within a very small tolerance $( \pm 1 \mathrm{~cm}$ or less). For this reason, it is a very effective tool in support of DIV. Figure 2 shows a scan of a nuclear material glove box, before and after modification. The areas highlighted in red and orange are areas that significantly differ from the original scan and were automatically identified by the 3DLR software. In viewing Figure 2, it is important to recall that the images are created by the 3DLR and are not actual photographs, although they are of photographic quality.

While the 3DLR has clearly shown its utility in DIV, especially for verifying large and complex process cells, one must bear in mind that scanning process areas that will become highly radioactive or inaccessible due to safety reasons will be difficult to re-verify (i.e. the highly radioactive process cells in a modern reprocessing plant). So, its use for this purpose may be limited. The 3DLR is still useful for collecting baseline verification data even for cells that may not be accessible in the future. The original 3DLR (Mark-I model) was fairly heavy and required the support of a $16 \mathrm{~kg}$ battery. The data logging laptop computer was also prone to interconnection and start-up glitches. The merging of multiple scans for a complex cell to create the reference images was not an easy task, as it still required considerable engineering skill and interpretation to merge these scans, using the operator provided equipment and cell installation drawings. In the meantime, JRC/Ispra has worked with the equipment supplier to address these issues in the newer Mark-II model, which rolled out in 2008. In this connection, it is important to note that the IAEA only has three 3DLR units, one of which permanently resides at RRP in Japan, and all of them the older Mark-I model. A summary of the pros, cons, issues, and relative cost for the purpose of comparison with other DIV tools is provided in Table 2. 


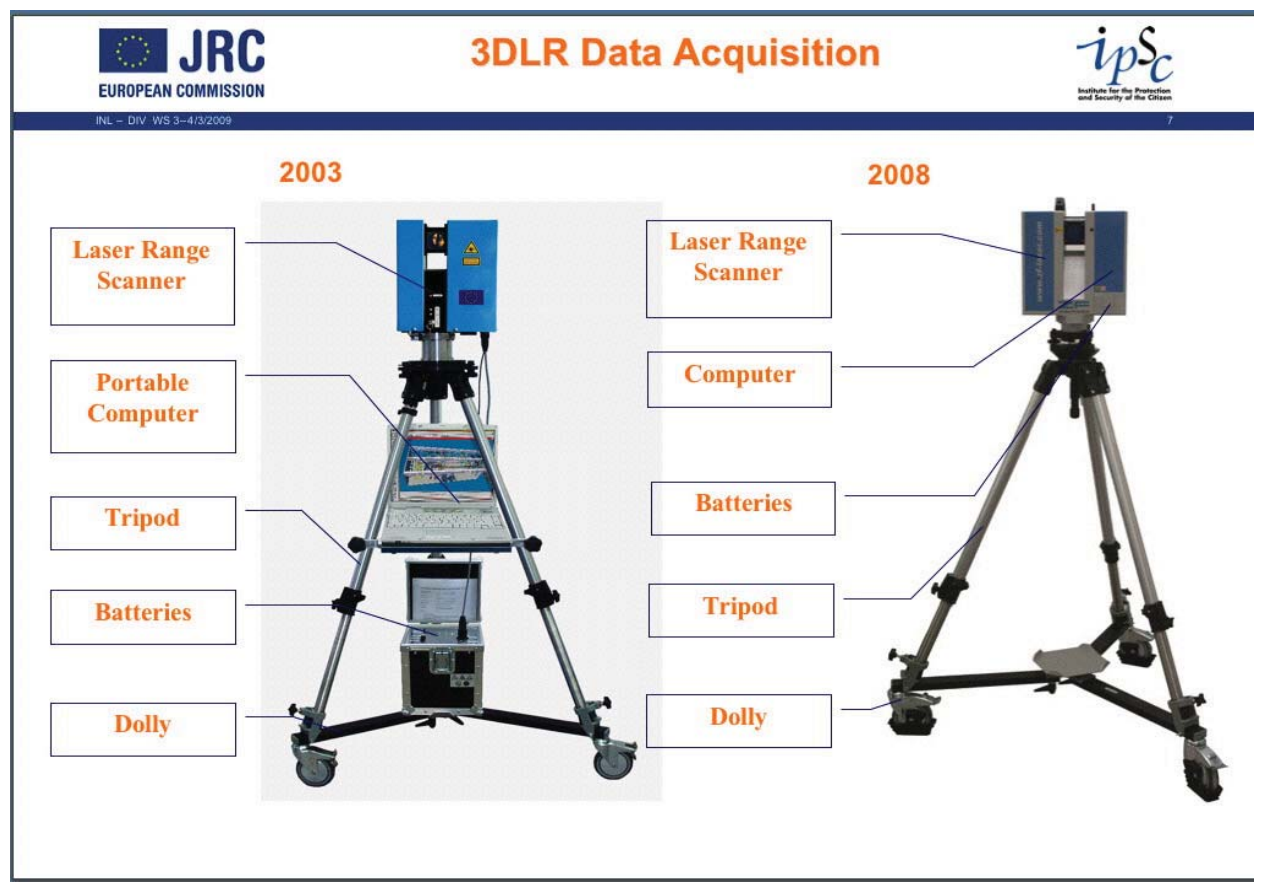

Figure 1: 3-Dimensional Laser Range Finder (3DLR) for DIV - Comparison of Mark-I (2003) and Mark-II (2008) Models.

(Source - European Commission Joint Research Centre - Ispra, Italy)

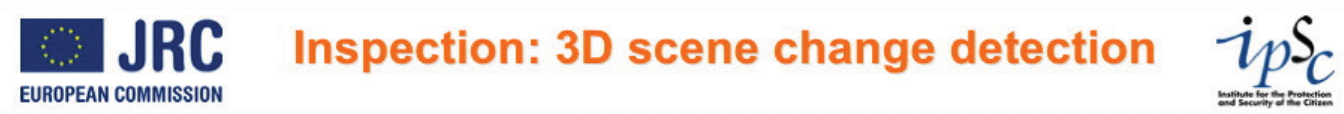

Example: JRC Ispra Test Facility

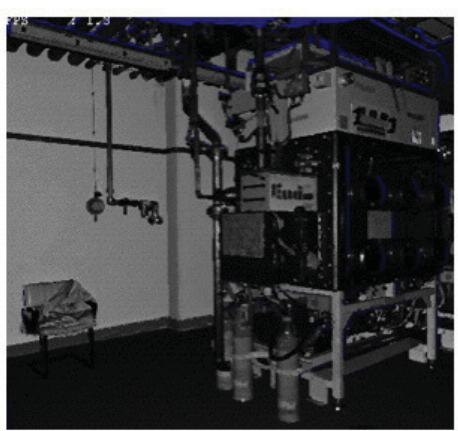

Reference

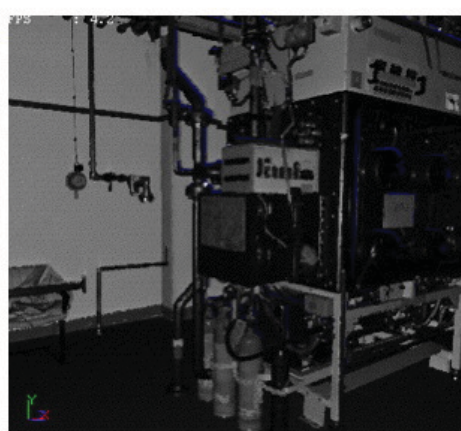

Verification

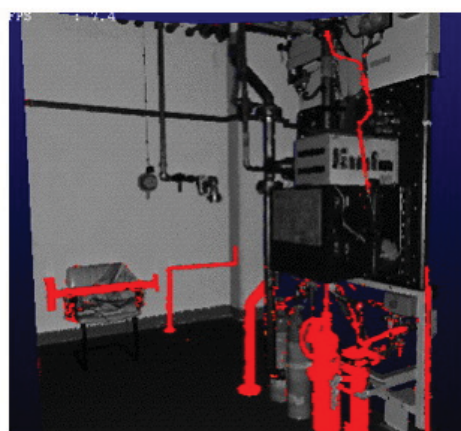

Differences

Figure 2: 3DLR Automated Change Scene Detection Feature. (Areas changed prior to reverification are automatically highlighted in red.)

(Source - European Commission Joint Research Centre - Ispra, Italy) 
Table 2: 3-Dimensional Laser Range Finder (3DLR) Pros and Cons.

\begin{tabular}{|l|l|}
\hline 3DLR & $\begin{array}{l}\text { 3-Dimensional Laser Ranger Finder (also called 3DLRF) } \\
\text { Infrared laser-based survey tool developed by JRC/Ispra in support of DIV activities } \\
\text { performed by the IAEA. }\end{array}$ \\
\hline Pros & $\begin{array}{l}\text { The 3DLR can survey a large and complex nuclear material process area or cell and } \\
\text { render a high-resolution 3-dimensional computerized model of the area. Subsequent use } \\
\text { of the instrument for re-verifying design information yields images that are automatically } \\
\text { compared by the computer, highlighting areas that have changed. The device has been } \\
\text { demonstrated by the IAEA in verifying design information at RRP from } 2003 \text { to the } \\
\text { present and was highly effective. }\end{array}$ \\
\hline Cons & $\begin{array}{l}\text { The original Mark-I model was heavy and clumsy to carry. The data logging computer } \\
\text { suffered from interface and start-up glitches. These problems are said to have been } \\
\text { corrected in the Mark-II model. The instrument is fairly expensive at approximately } \\
\text { \$120K, and requires the use of a stand-alone workstation for reviewing stored reference } \\
\text { models, if a large number of reference models are created. }\end{array}$ \\
\hline Comments & $\begin{array}{l}\text { Despite its great utility and demonstrated capability, the IAEA only has three 3DLR units, } \\
\text { one of which permanently resides at RRP. The number of inspectors trained in its use is } \\
\text { estimated to be about 40 out of 250 designated inspectors, of which approximately 10 are } \\
\text { no longer with the IAEA. Broader use of this instrument worldwide is encouraged. } \\
\text { However, this will require the acquisition or donation of additional instruments and } \\
\text { training. }\end{array}$ \\
\hline $\begin{array}{l}\text { 3DLR Instrument (Mark-II), per unit* } \\
\text { *(depending on number of units ordered) } \\
\text { Stand-alone computer workstation for reviewing and merging scans }\end{array}$ \\
\hline Cost
\end{tabular}

\subsection{Compton Gamma Radiation Imaging for Use in DIV}

\section{There is a need to detect undeclared or concealed process piping and vessels and associated nuclear material processing.}

While the 3DLR very effectively maps the contours and features of visible equipment, pipes, and interconnections, there is a need to detect concealed piping and equipment that may be used for undeclared processing, or which may be enhancing the processing capacity of a facility. To address this need, researchers at Lawrence Livermore National Laboratory (LLNL) and Lawrence Berkley National Laboratory (LBNL) developed a Compact Compton Imager (CCI), shown in Figure 3. The CCI was created by integrating a large number of radiation-sensitive semiconductors, producing a high spatial-resolution imaging array that can be used to detect gamma radiation emitting hotspots. U.S. DOE National Laboratory researchers demonstrated the CCI at LLNL, detecting a 1-meter long encapsulated Eu-152 source concealed in a controlled laboratory, simulating an undeclared radioactive process pipe as shown in Figure 4. 


\section{We are developing a compact Compton imager}

- The Compton camera determines the direction of the gamma ray by tracking its interactions inside a multilayered detector system.

- Compton imaging provides 180 deg field of view, 2 deg angular resolution (3 $\mathrm{cm}$ at $1 \mathrm{~m}), 2 \mathrm{keV}$ energy resolution, and can image the $186 \mathrm{keV}{ }^{235} \mathrm{U}$ line and the 375 and $414 \mathrm{keV}{ }^{239} \mathrm{Pu}$ lines.

- It takes $5 \mathrm{~min}$ to image $1 \mathrm{~g}{ }^{239} \mathrm{Pu}$ in a $6 \mathrm{~cm}$ pixel, $2 \mathrm{~m}$ away

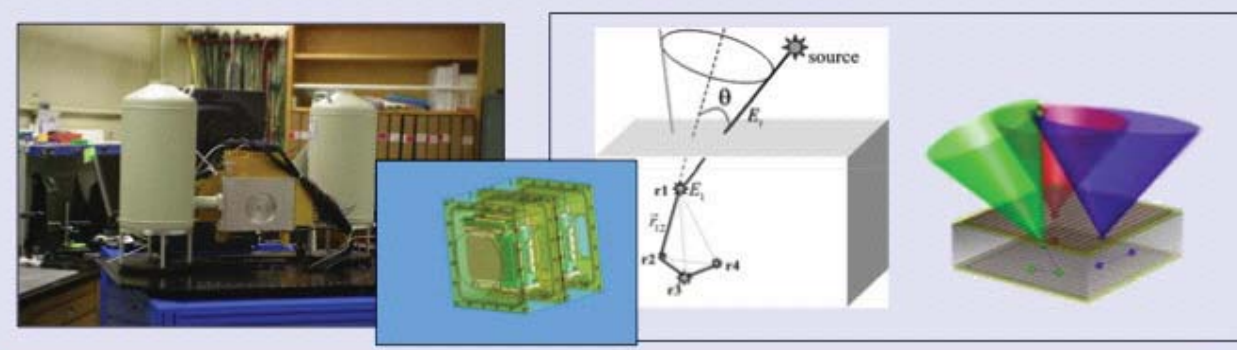

We have built and tested the first Compton camera to take advantage of the new semiconductor strip detector technology that enables high-spatial-resolution, collimatorless imaging.

Lawrence Livermore National Laboratory

Figure 3: Compact Compton High Resolution Gamma Imaging Device.

(Source - Lawrence Livermore National Laboratory)

\section{Measurements demonstrate gamma-ray imaging of materials in pipes}

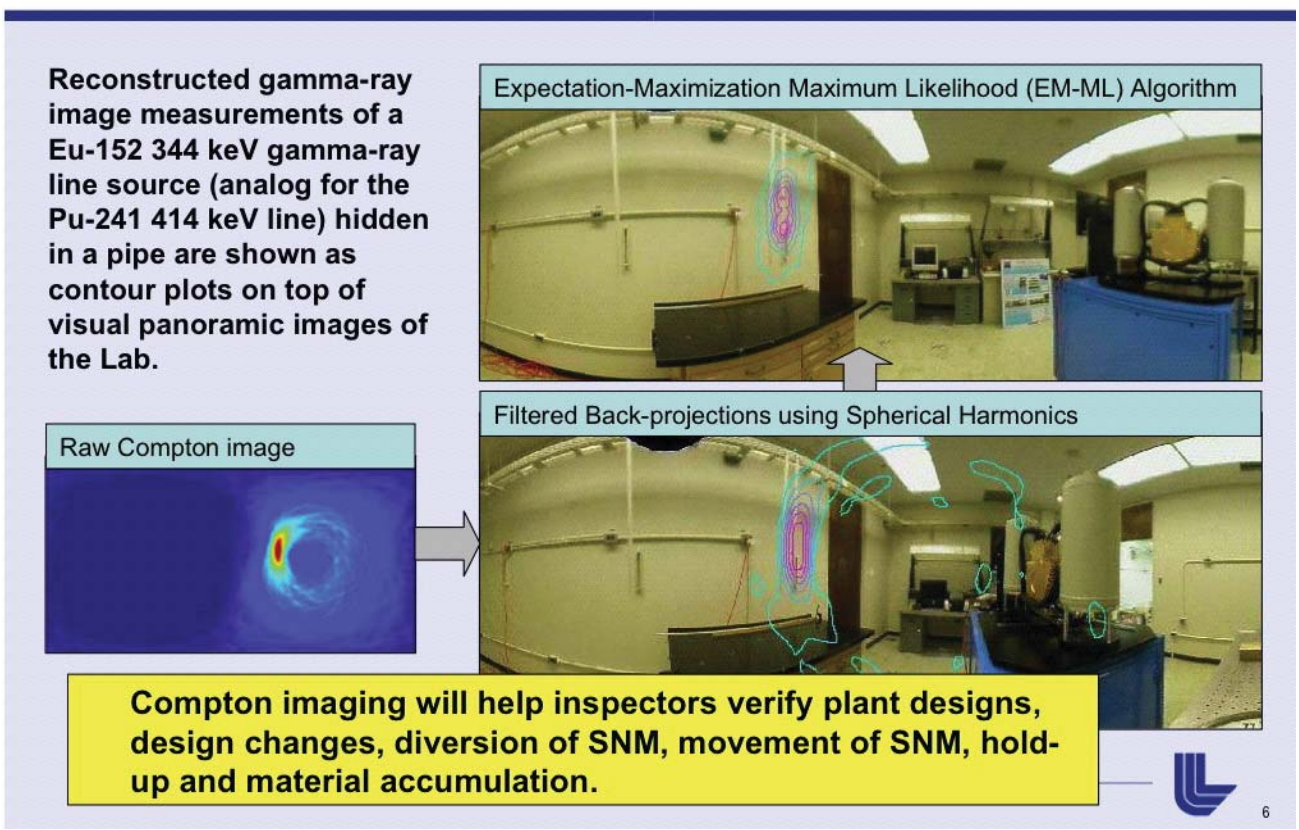

Figure 4: Compact Compton Imager Identifying Radioactive Hotspot. (Source - Lawrence Livermore National Laboratory) 
The raw image produced by the integrated semiconductor detectors is enhanced and more effectively visualized in space with filtered back projections using spherical harmonics, performed using application specific algorithms. Use of the CCI, or Gamma Camera, is further addressed in Section 4.3, "Laser Range Finder with Gamma Camera," where it is combined with a 3DLR. In this instrument hybrid, it combines the detailed mapping and survey capability of the 3DLR with the high resolution gamma radiation detection and visualization of the CCI. A summary of the pros, cons, issues, and relative cost for the purpose of comparison is provided in Table 3 .

Table 3: Compact Compton Imager (CCI) Pros and Cons.

\begin{tabular}{|l|l|}
\hline $\begin{array}{l}\text { Compact Compton } \\
\text { Imager (CCI) }\end{array}$ & $\begin{array}{l}\text { A newly developed high-resolution gamma radiation detection and imaging } \\
\text { device that uses a large integrated array of cryogenically cooled strips of } \\
\text { semiconductor detectors. The CCI, also called a Gamma-Camera, can be used to } \\
\text { detect and visualize the presence of gamma radiation emitting hot-spots in } \\
\text { three-dimensional space. Consequently, it can be used in DIV to detect the } \\
\text { presence and map undeclared or concealed process piping and equipment } \\
\text { handling highly radioactive material. }\end{array}$ \\
\hline Pros & $\begin{array}{l}\text { The CCI provides unprecedented resolution in radiation detection and mapping } \\
\text { in three-dimensions, using a large array of integrated semiconductor radiation } \\
\text { detectors. IAEA inspectors currently do not possess such a sophisticated tool for } \\
\text { detecting and visualizing undeclared or concealed process piping and equipment } \\
\text { handling highly radioactive material. }\end{array}$ \\
\hline Cons & $\begin{array}{l}\text { The CCI is still a developmental tool and is quite bulky due to the current size of } \\
\text { the semiconductor array and the cryogenic cooling system. However, the size of } \\
\text { these two subsystems is expected to be reduced through miniaturization efforts. } \\
\text { Detector measurement dwell time can be on the order of 30 minutes to several } \\
\text { hours, depending on the level of detection or sensitivity required. }\end{array}$ \\
\hline Comments & $\begin{array}{l}\text { While the CCI is an important achievement in radiation detection and hot-spot } \\
\text { visualization, for the purpose of DIV, the device may be more effective in } \\
\text { combination with the 3DLR, as discussed in Section 4.3. }\end{array}$ \\
\hline Cost & $\begin{array}{l}\text { CCI Gamma Camera (Mark-II)* } \\
*(\text { depending on number of units ordered) }\end{array}$ \\
\hline
\end{tabular}

\subsection{Laser Range Finder with Gamma Camera (Gamma-LIDAR)}

There is a need to detect undeclared or concealed process piping and vessels and associated nuclear material processing.

To address the need noted in Section 4.2, a team of researchers at LBNL and LLNL modified a 3DLR with a high resolution Compact Compton Imager. ${ }^{14,15}$ Application specific data analysis algorithms were developed to make use of the Laser Range Finder data, as obtained with the 3DLR scanner. To demonstrate the system, a 1-meter long Eu-152 source was concealed in the laboratory under controlled conditions to simulate an undeclared process pipe containing nuclear material, as shown in Figure 5. Figure 6 shows how the Gamma-LIDAR effectively detected the pipe in a wide open laboratory setting. 


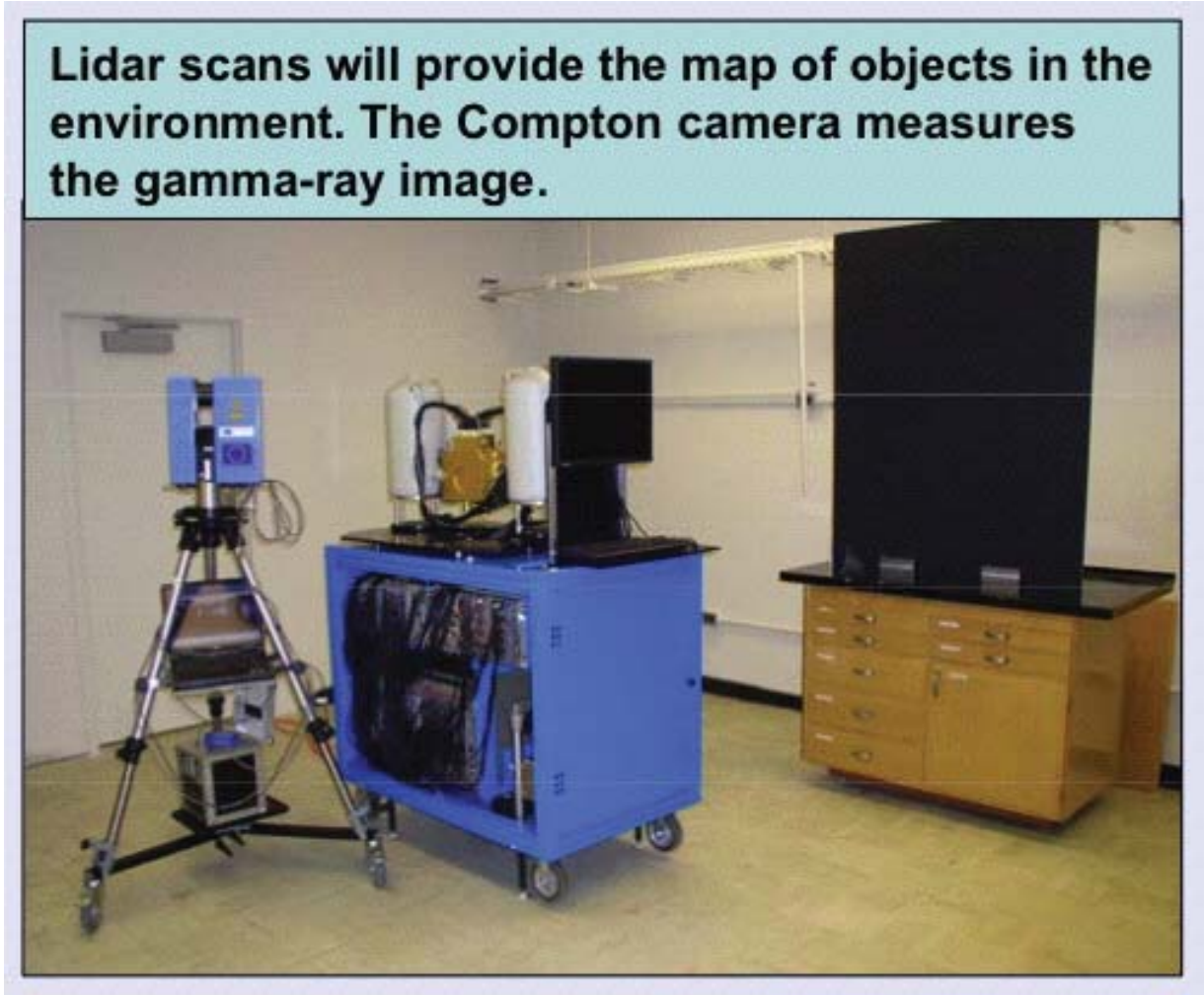

Figure 5: Gamma-LIDAR (3DLR Modified with CCI).

(Source - Lawrence Livermore and Lawrence Berkley National Laboratory)

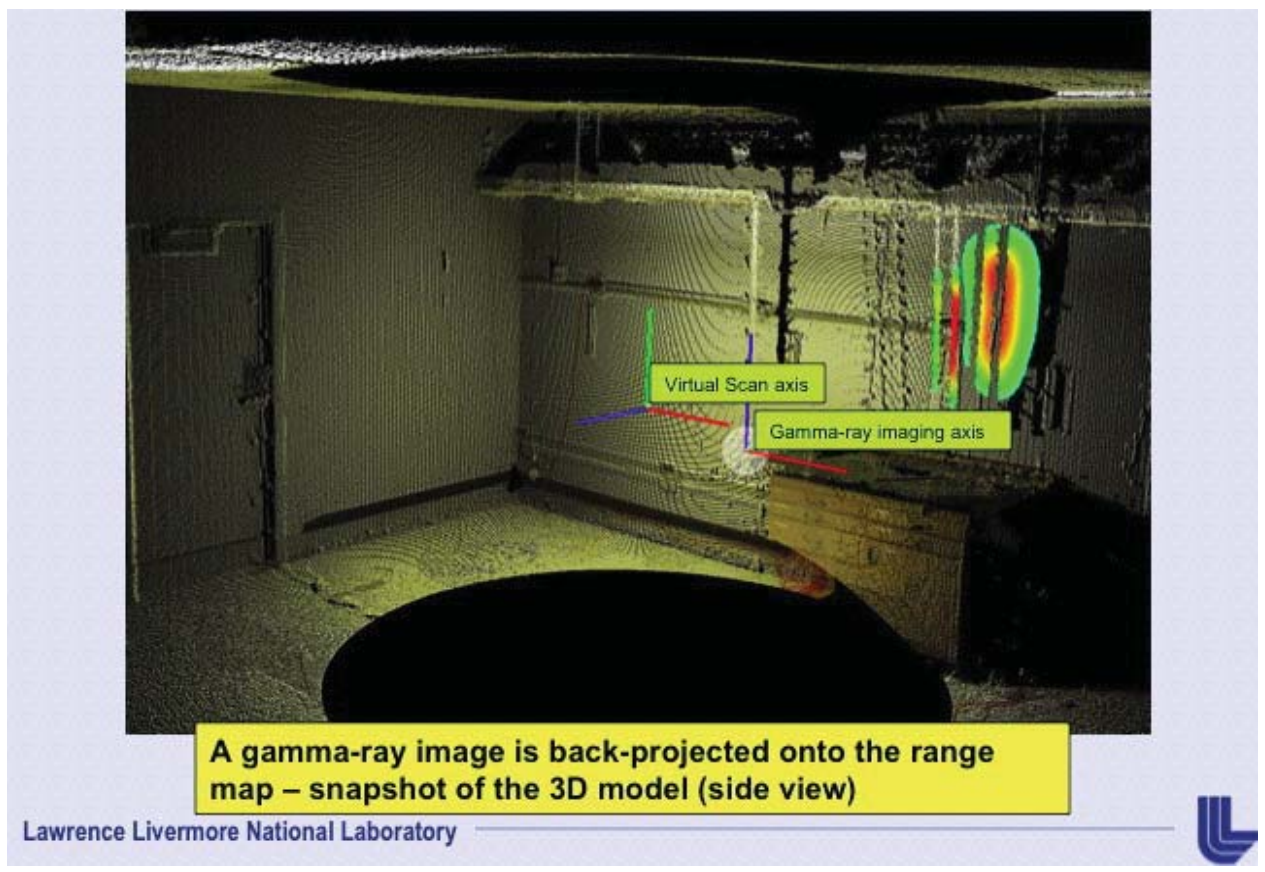

Figure 6: Gamma Radiation Map Produced by the Gamma-LIDAR. (Source - Lawrence Livermore and Lawrence Berkeley National Laboratory) 
Currently, the Gamma-LIDAR system requires a dwell or measurement time of 30 minutes to several hours, which is considerably greater than the typical scan time of 3 to 5 minutes for the 3DLR. However, the Gamma-LIDAR is envisioned for special applications, where there is a large or dense installation of process equipment and the inspector is attempting to determine in a more systematic manner if any equipment is being used for undeclared nuclear processing, effectively increasing the processing capacity of the facility. With additional development and testing, researchers at LBNL and LLNL hope to develop a Mark-II version of this instrument with greater resolution and shorter measurement dwell time. They are also considering developing a version of this instrument suitable for detecting the presence of HEU in a gas centrifuge enrichment plant, based on the gamma emission from the U-235 isotope. A summary of the pros, cons, issues, and relative cost for the purpose of comparison is provided in Table 4.

Table 4: Gamma-LIDAR Pros and Cons.

\begin{tabular}{|l|l|l|}
\hline Gamma-LIDAR & $\begin{array}{l}\text { 3-Dimensional Laser Range Finder Modified with a Compton-Scattering Compact } \\
\text { Imager for High Resolution Gamma Imaging. }\end{array}$ \\
\hline Pros & $\begin{array}{l}\text { Unlike the 3DLR, the Gamma-LIDAR combines gamma imaging with } \\
\text { three-dimensional laser scanning and can detect the presence of piping or vessels } \\
\text { processing undeclared nuclear material. This tool could potentially address the need } \\
\text { to detect undeclared or concealed process vessels and piping, if they contain } \\
\text { significant gamma emitting nuclear material. }\end{array}$ \\
\hline Cons & $\begin{array}{l}\text { The system is still under development, although initial tests are promising. } \\
\text { Currently, the measurement dwell time is relatively high at 30 minutes to several } \\
\text { hours. The current development model is bulky and would need to be ruggedized } \\
\text { and made more compact for field use. }\end{array}$ \\
\hline Comments & $\begin{array}{l}\text { Continued development of this system is recommended to demonstrate if it can be } \\
\text { effectively used to detect equipment processing undeclared nuclear material in an } \\
\text { actual nuclear facility or practical application. Further development of this system } \\
\text { to detect the presence of HEU in a gas centrifuge plant appears worth consideration. }\end{array}$ \\
\hline Cost & $\begin{array}{l}\text { CCI Gamma-Camera (Mark-II) } \\
\text { (includes cost of 3DLR system) }\end{array}$ & \$500K \\
\hline
\end{tabular}

\subsection{Enhanced Ground Penetrating Radar for DIV}

There is a need to detect undeclared or concealed process piping and vessels and associated nuclear material processing, which may be concealed in concrete walls or pads or buried in soil.

The Workshop Team discussed the use of Ground Penetrating Radar to address the need during DIV to detect undeclared or concealed process equipment that might be augmenting the capacity or function of the facility. Historically, GPR was used at Hanford and other DOE Sites to explore for buried waste tanks, drums, and improperly disposed equipment. It was reasonably effective for this purpose. The IAEA also has had some limited experience with GPR, primarily to help establish the correctness and completeness of the state-wide declaration of nuclear material and activities in countries that have implemented the Additional Protocol (AP) to their safeguards agreement. Unfortunately, the GPR unit used by the IAEA produced a planar image that was often difficult to resolve to detect buried objects and was highly dependent on soil and substrate conditions. ${ }^{16}$ The GPR unit was also heavy, difficult to move from place to place, and required a trained technician to operate the system and interpret the imagery. The Pacific Northwest National Laboratory (PNNL) and other partners developed application specific algorithms to enhance GPR to improve image resolution and, more importantly, to render the image in 3-dimensions. This greatly facilitated interpretation of the image. Subsequently, the enhanced GPR system was used at 
the Hanford DOE Site and was much more effective in discriminating buried objects, vessels, and improperly disposed waste drums. While safeguards inspectors do not routinely hunt for buried objects, there is still a need for such a tool in the DIV arsenal to hunt for and discriminate buried and concealed objects. This is especially the case for establishing the completeness and correctness of a country's state-wide declaration of nuclear material and activities, and to ascertain the size and capacity of declared nuclear facilities and sites during DIE/DIV. A summary of the pros, cons, issues, and relative cost for the purpose of comparison is provided in Table 5.

Table 5: Enhanced Ground Penetrating Radar (GPR) Pros and Cons.

\begin{tabular}{|l|l|}
\hline Enhanced GPR & $\begin{array}{l}\text { Ground Penetrating Radar, enhanced with application-specific algorithms for } \\
\text { improved image resolution and 3-dimensional imaging. }\end{array}$ \\
\hline Pros & $\begin{array}{l}\text { Unlike the 3DLR, enhanced GPR can be used to detect and image vessels, piping, } \\
\text { and process equipment buried in the soil that may have been evidence of previous } \\
\text { nuclear material processing or undeclared interconnections with other facilities (for } \\
\text { augmenting processing capacity). The technique has been successfully demonstrated } \\
\text { in detecting improperly discarded waste drums and equipment at the Hanford Site. }\end{array}$ \\
\hline Cons & $\begin{array}{l}\text { An enhanced GPR system would need to be further optimized for DIV application. } \\
\text { The IAEA has proposed using this system for detecting undeclared piping and } \\
\text { process connections concealed in concrete, but the system would need to be } \\
\text { optimized for this purpose. While it has been used to successfully detect buried } \\
\text { objects in desert soil, its effectiveness depends greatly on the nature of the soil and } \\
\text { substrate and the depth of the buried object. }\end{array}$ \\
\hline Comments & $\begin{array}{l}\text { Enhanced GPR has been used effectively to detect shallow buried objects in desert } \\
\text { soil. Consequently, it is worth enhancing for DIV applications to detect concealed } \\
\text { objects in concrete and in a variety of soils at varying depths. While it may not be a } \\
\text { commonly used tool, it seems to be a necessary complement in the arsenal of tools } \\
\text { for DIV to detect buried and concealed process equipment, piping, and debris from } \\
\text { undeclared nuclear material processing. }\end{array}$ \\
\hline Cost & $\begin{array}{l}\text { Enhanced GPR (Mark II) } \\
\text { (optimized for DIV applications) }\end{array}$ \\
\hline
\end{tabular}

\subsection{Virtual Reality (VR) for DIV Reference Facility Models}

\section{There is a need to have a reference model or file of the facility to compare with the current facility to detect safeguards relevant changes in configuration and/or operation.}

One of the most important needs when performing DIV is to have a reference model of the facility constructed from the design information declared by the facility operator - based on facility diagrams, equipment layout, and installation drawings, including photos of essential process equipment. This is what the safeguards inspectors accumulate as they collect the information for safekeeping at the facility, or in secured facility files at IAEA Headquarters in Vienna, Austria. The challenge is that this loose collection of declared information is less usable as pieces, rather than as an integrated whole. The loose collection of pieces of information also does not reflect the progress or questions raised in previous DIV activities. This information is typically recorded in the IAEA Safeguards Department Computerized Inspection Report (CIR) database. LANL developed a computer based tool for developing integrated reference facility models for DIV. These Virtual Reality (VR) models maintain a computerized record that can be used in real time, to make notes and maintain records from previous DIVs. ${ }^{17}$ 


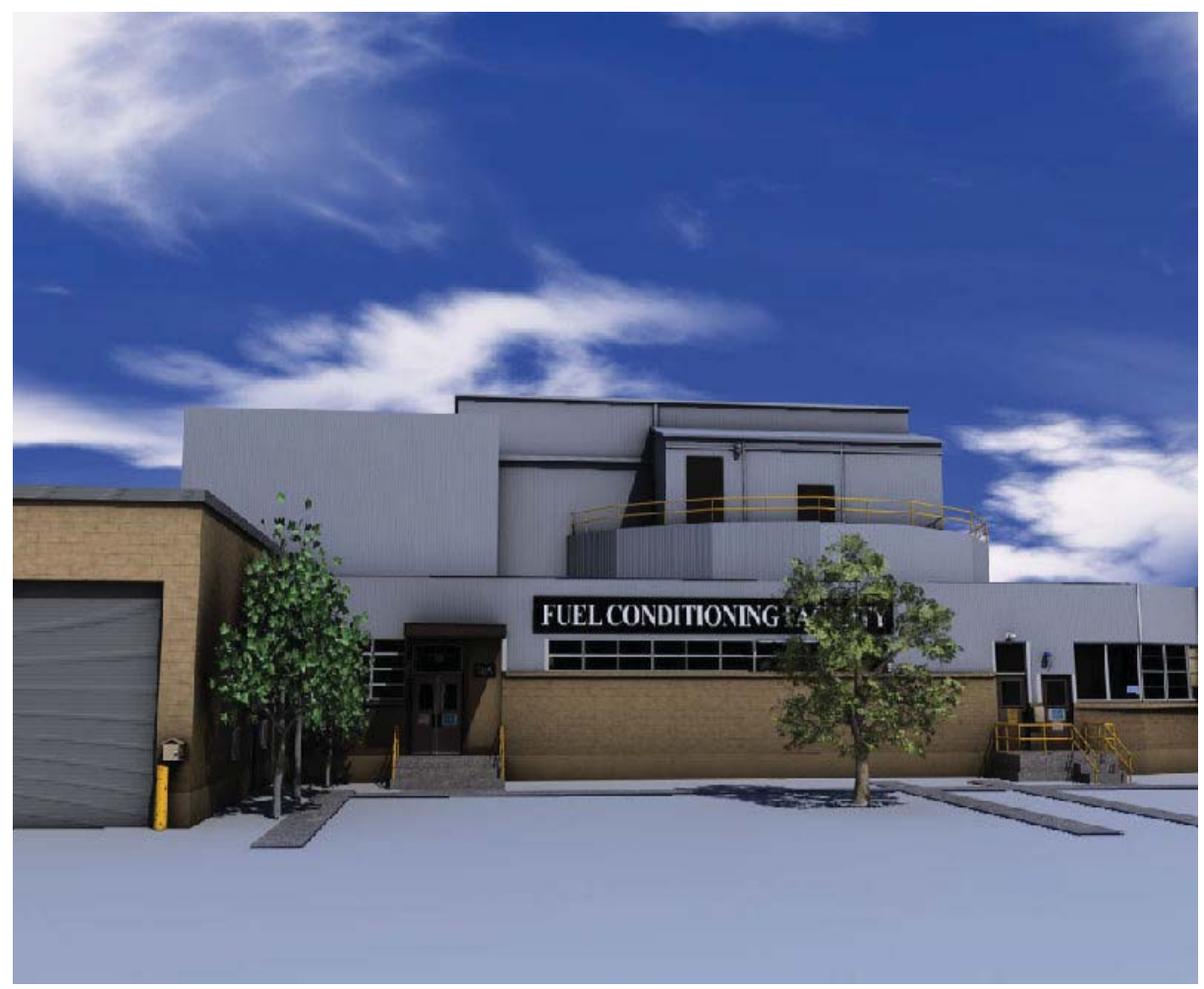

Figure 7: Virtual Model of Idaho Fuel Conditioning Facility (FCF).

(Source - Los Alamos and Idaho National Laboratories)

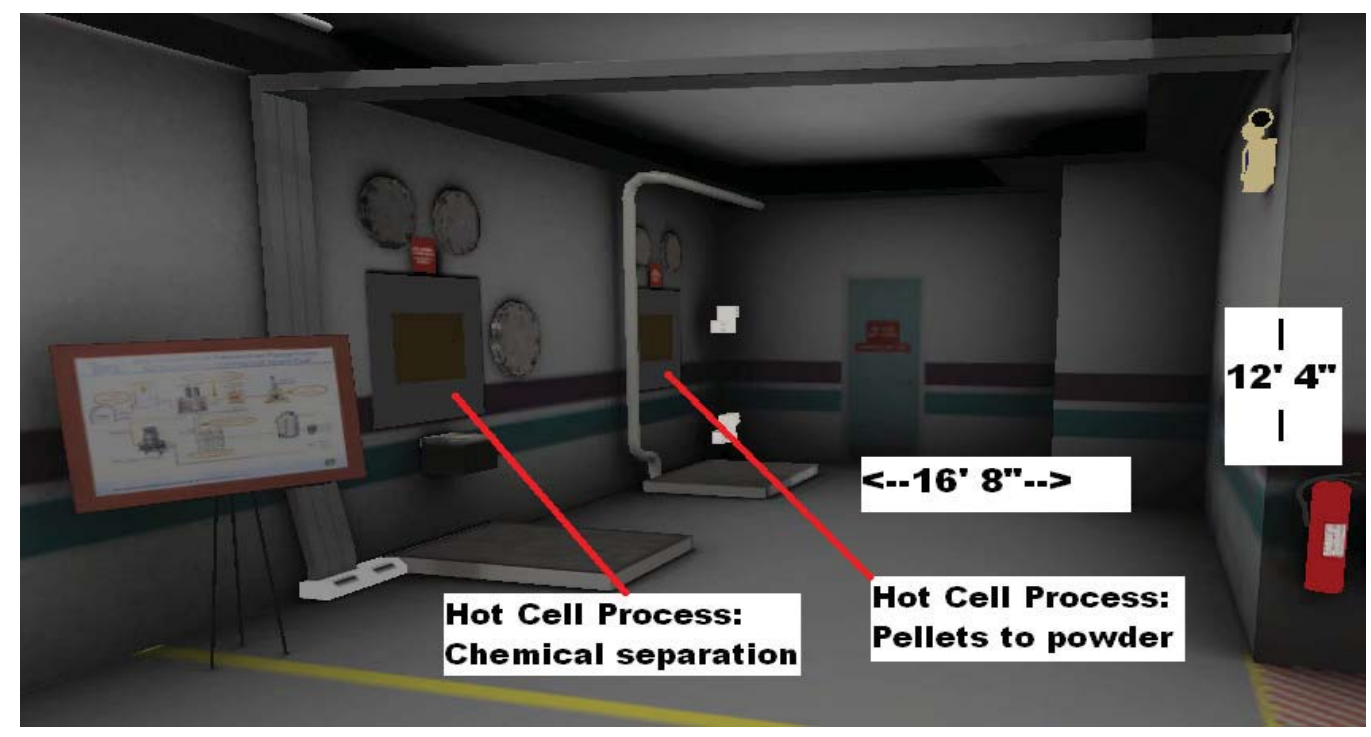

Figure 8: Virtual Model of Hot Cell Operator Work Area.

(Source - Los Alamos and Idaho National Laboratories) 
The rendering of facility models using VR has been tested and demonstrated potentially for DIE/DIV, using the hot cell facilities at the ORNL and the pyro reprocessing Fuel Conditioning Facility at INL. The VR technology uses photo-realistic 3-D graphical components based on information in the DIQ and from operator provided drawings and photographs in an immersive and interactive computer based application. A safeguards inspector would use the VR reference model on a portable laptop and "walk through" the model, as if they were walking through the actual facility.

In walking through the model, the inspector can open doors, hatches, and even virtually "enter" contaminated and highly radioactive process areas to view the essential process equipment. As a result, inspectors exploring virtual models of a facility can develop insight and intuition in the function and capabilities of facilities before ever setting foot in the actual facility. An example of the VR rendering is shown in Figures 7 and 8. What is important to note is the fidelity of the design detail that can be captured on the interior, as well as the interior.

The advantages of using VR generated reference facility models are that they: i) Are portable and could be carried into the facility during DIV; ii) Contain detailed reference information regarding the essential process equipment; and iii) Could be easily annotated to record DIV questions or previous verification activities. Additionally, they could be used by IAEA inspectors in Vienna for pre-inspection briefing, training, and debriefing. It is important to reiterate that the physical features and characteristics of the 3-D virtual model are based on actual facility design information as declared by facility operator through the national authorities - i.e., information currently contained in the DIQ and as provided by plant and equipment design, fabrication, and installation drawings and photographs. While the term "virtual reality" might suggest artificial, it must be recognized that the VR model would be based on the same tools and pieces of information that the safeguards inspector currently uses for preparing and performing the DIV. The advantage of the VR facility reference model is that it would contain this information in an integrated package. However, the handling and security of portable high quality reference models containing detailed design information will concern most nuclear facility operators and national authorities. The same level of protection provided for design information currently would have to be extended to the composite reference models as well. What is noteworthy is that the IAEA is already handling facility specific sensitive design information for the purpose of implementing nuclear safeguards. The advantage of the composite reference models is that all of the information for a single facility could be combined in one secured file. As the IAEA performs DIE/DIV at larger and more complex facilities, there will be a need to combine this information in single files so that it is more easily retrieved and usable by the inspector. However, the security concerns of the facility operator and national authorities will need to be addressed and satisfied.

What is noteworthy about projected VR modeling as a DIV tool for building facility reference models is that it is primarily a labor intensive process, rather than a discrete instrument like the previous tools discussed. For the sake of comparison, a cost has been estimated in Table 6 . However, it must be recognized that this reflects principally labor and not equipment per se, although the cost for licensed use of the VR modeling software, tools, and computer has been included. Since the labor will depend on the size and complexity of the facility, the estimate provided is for a modest-sized nuclear facility, such as the fuel and material examination hot cells at ORNL and the Fuel Cycle Facility (FCF) at INL. While it may not be practical to construct VR reference facility models for each facility inspected by the IAEA, this tool may be appropriate for very large and complex nuclear facilities, especially for areas that are inaccessible due to radiation or radioactive contamination (such as hot cells or glove boxes). A summary of the pros, cons, issues, and relative cost for the purpose of comparison is provided in Table 6 . 
Table 6: Virtual Reality (VR) Modeling for DIV Pros and Cons.

\begin{tabular}{|l|l|}
\hline $\begin{array}{l}\text { Virtual Reality } \\
\text { Modeling }\end{array}$ & $\begin{array}{l}\text { Projected Virtual Reality (VR) Modeling for constructing computer-based reference } \\
\text { facility models for use by inspectors during DIV. }\end{array}$ \\
\hline Pros & $\begin{array}{l}\text { Reference facility models constructed using projected VR would be based on operator } \\
\text { declared design information and supporting drawings, diagrams, and photographs as } \\
\text { currently provided to the IAEA. Such models would be portable and would permit } \\
\text { interactive use by the inspector in the field (i.e., for referring to the equipment layout } \\
\text { and configuration in inaccessible areas and previously noted DIV activities). }\end{array}$ \\
\hline Cons & $\begin{array}{l}\text { The process of creating reference models of facilities is more time-consuming than } \\
\text { current DIV activities and can take several additional days of field verification effort } \\
\text { to confirm the design features being built into the model. It does not appear to be a } \\
\text { tool that would be widely used for DIV at every nuclear facility. However, it does } \\
\text { seem very appropriate for large and complex facilities and where the DIV effort will } \\
\text { already be significant during construction. }\end{array}$ \\
\hline Comments & $\begin{array}{l}\text { Projected VR modeling for making reference models of facilities for use during DIV } \\
\text { appears to be coming of age, as was demonstrated at FMEF at ORNL and FCF at } \\
\text { INL. It appears to be especially useful for providing virtual access to areas of the } \\
\text { facility that are, or will be, inaccessible. In addition to the application for DIV, VR } \\
\text { reference models would be extremely useful for pre-inspection training, briefing, and } \\
\text { post-inspection debriefing. Broader applications of this technology in support of } \\
\text { nuclear safeguards are quite apparent. }\end{array}$ \\
\hline Cost & $\begin{array}{l}\text { Computer and Software User License (note specific software tools) } \\
\text { VR Rendered Facility Model (per facility) } \\
\text { (small to medium-size nuclear facility) }\end{array}$ \\
\hline
\end{tabular}

\subsection{Change Detection Software for Use in DIV}

\section{There is a need to detect changes in existing nuclear facilities using old design information including reference hardcopy photographs.}

The IAEA has a need to detect changes at nuclear facilities during DIV, using older reference documents, often including Polaroid photographs secured at the facility. Inspectors use these reference images when they inspect the facility during re-verification of the facility design information and during Limited Frequency Unannounced Access (LFUA) at enrichment plants under a Hexapartite Safeguards (HSP) Approach. ${ }^{j}$ However, this activity is highly dependent on the awareness and capability of the particular inspector to observe changes in what they see in the reference photo, versus the current facility and installation. This can be extremely challenging in facilities with very dense process piping installations, as shown by example in Figure 9, and has driven the demand for a tool that could be used to compare the reference photo to what the inspector actually sees.

To address this need, the Idaho National Laboratory (INL) has developed Change Detection Software (CDS) for planar images. Existing reference photos that support DIV or LFUA activities could be digitally scanned under controlled and secure conditions in the presence of the facility operator and

\footnotetext{
${ }^{j}$ The IAEA Hexapartite Safeguards Project (HSP) involved the six major partners outside of the Soviet Union and China that possessed uranium enrichment technology in the 1980s. The purpose of the project was to devise an acceptable safeguards approach for gas centrifuge enrichment plants. A major safeguards measure developed under this project was the Limited Frequency Unannounced Access (LFUA), whereby IAEA safeguards inspectors could access the enrichment cascade hall at short notice to detect undeclared re-configuration of header piping or removal of $\mathrm{UF}_{6}$.
} 
national authorities. These reference scans could be kept at the facility on portable computer readable media, secured with the other design information kept on site. On a subsequent inspection, the inspector would take a new digital photograph of the area being inspected and upload it to a portable laptop computer. The new image could then be digitally compared to the reference photo image from the scanned photograph, with the CDS highlighting areas that have significantly changed. To prevent false alarms, the difference tolerance can be adjusted, so that the inspector does not waste time looking at areas that differ in lighting, contrast, or triggered by artifacts in the reference or current photo. An example of this comparison is shown in Figure 9, using a file photo from a large gas centrifuge enrichment plant. For the sake of this comparison, the other image was digitally altered slightly as it might appear in real life. The CDS was effective in detecting these very subtle changes, which are nearly undetectable to the naked eye. Since there is no quality control check for the use of human-based visual comparison, it is possible for the inspectors to actually miss changes in the piping and process configuration. The use of scanners to digitize existing reference Polaroid photos for DIV and LFUA, together with laptop computer-based Change Detection Software, converts this safeguards activity from being qualitative to one being systematic and quantitative. In essence, it would modernize the activity. The main use of this technology would be where the IAEA already has reference photo images, such as in DIQ files pre-positioned at nuclear facilities, as well as in support of LFUA at gas centrifuge enrichment plants (GCEP).
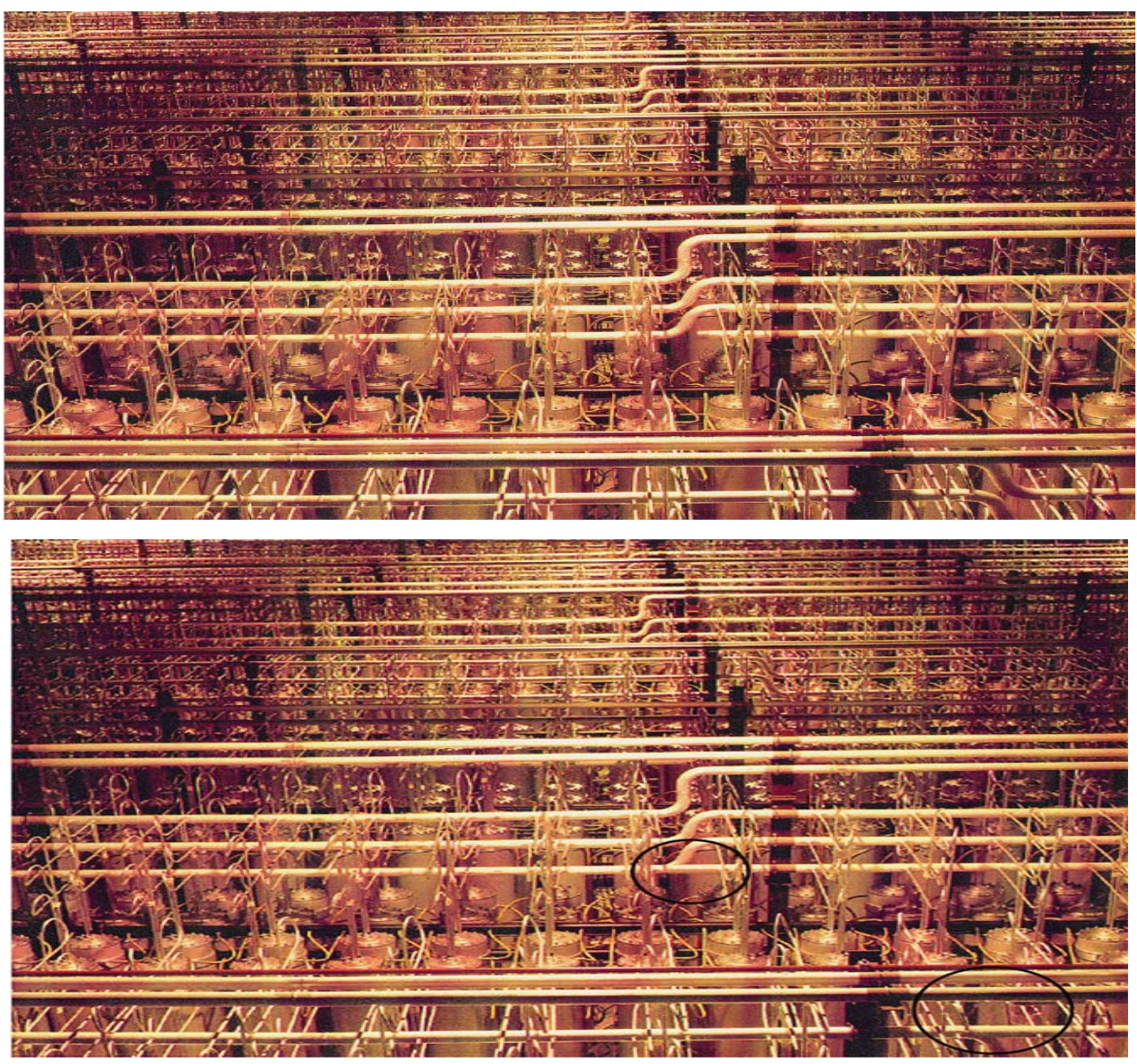

\section{Figure 9: Comparison of Reference Photo for Enrichment Cascade Hall with Altered Image Using Change Detection Software}

(Source - URENCO Brochure and Idaho National Laboratory) 
Table 7: Planar Image Change Detection Software (CDS) Pros and Cons.

\begin{tabular}{|c|c|}
\hline $\begin{array}{l}\text { Planar Image } \\
\text { Change Detection } \\
\text { Software }\end{array}$ & $\begin{array}{l}\text { Laptop Computer-based Planar Image Change Detection Software (CDS) for } \\
\text { comparing digitized reference images and photos with actual observations recorded } \\
\text { on digital camera during re-verification of facility design information. }\end{array}$ \\
\hline Pros & $\begin{array}{l}\text { The platform for the CDS is an inexpensive commercially available laptop } \\
\text { computer. The CDS has been practically tested and is ready for inspector } \\
\text { evaluation and practical demonstration. CDS could help make extensive files of } \\
\text { existing reference photos and images more useful than they are currently. The use } \\
\text { of CDS is more systematic and quantitative than the current visual observation } \\
\text { activity, which is qualitative and highly dependent on the safeguards inspector. }\end{array}$ \\
\hline Cons & $\begin{array}{l}\text { Full use of CDS requires that existing photos and reference images be scanned and } \\
\text { stored on computer-based media. This information is safeguards confidential, } \\
\text { which presents the possibility that it could be removed. However, it must also be } \\
\text { remembered that the information as it currently exists is also portable and could } \\
\text { potentially be removed from the facility. This is why use of this reference } \\
\text { information is controlled by the facility operator and the national nuclear } \\
\text { authorities. It would take years to digitize the photos and references images stored } \\
\text { in DIQ files at nuclear facilities and at IAEA Headquarters in Vienna. However, the } \\
\text { modernization of any existing system takes time and effort. The use of photos and } \\
\text { reference images on paper-based media is on borrowed time. The sooner these } \\
\text { records are digitized, the sooner they can be used more effectively. (The original } \\
\text { photos and reference images could always be archived in central files in the IAEA } \\
\text { Safeguards Department.) }\end{array}$ \\
\hline Comments & $\begin{array}{l}\text { It is perhaps surprising that CDS was not proposed or used sooner for this purpose. } \\
\text { The IAEA uses CDS in reviewing video surveillance media and in using the 3DLR. } \\
\text { However, these tools are of little value when referring to existing photos or } \\
\text { reference images on paper. Planar image CDS appears to be an appropriate tool for } \\
\text { detecting changes at a large number and wide variety of nuclear facilities, including } \\
\text { during LFUA at gas centrifuge enrichment plants. }\end{array}$ \\
\hline Cost & $\begin{array}{l}\text { CDS Laptop Computer and Software (Mark-II)* } \\
*(\text { Depending on number of units ordered) }\end{array}$ \\
\hline
\end{tabular}

\subsection{Robotics in Support of DIV}

There is a need to re-verify the design information in areas of nuclear facilities that may not be accessible to safeguards inspectors due to high radiation, or for other operational and safety reasons.

An advanced technology that could potentially be used in support of nuclear facility Design Information Verification is robotics. The safeguards need that would be addressed is verifying sensitive facility design features in areas that are inaccessible to humans due to high radiation or radioactive contamination, especially plutonium (alpha) contamination. DIV is an application area where robots could potentially provide benefits in terms of time, cost, safety, and quality of data. However, these benefits can be realized only if the prospective users provide input for the robots to be designed to meet specific needs. In 2001, INL successfully deployed a teleoperated robotic system to characterize radiation and contamination levels in an area that had been closed to human entry for many years. ${ }^{18}$ Although the 2001 deployment was a success in terms of human exposure, time, and money, evaluation of the operation exposed severe limitations of the master-slave strategy employed, including lapses in communication, 
limitations to the spatial accuracy of collected data, and overall system usability issues that forced personnel to enter the environment. ${ }^{19}$ Consequently, researchers have since developed a mixed-initiative command and control architecture, which has been implemented on a variety of ground vehicles ranging from small handheld systems to larger All Terrain Vehicles (ATV). An example of a smaller robotic-ATV is shown in Figure 10. Researchers have employed an iterative "Design/Test/Design" philosophy to evaluate the robot's usability, orientation and positioning accuracy, and effectiveness of auxiliary features.

Human Factors studies in the area of human computer interaction (HCI) and human machine interaction (HMI) have revealed that many complex tasks are more successfully performed when the system is designed to support the needs of the human rather than eliminating the human from the system. ${ }^{20,21}$ Consequently, it is believed that robotic assistance should be a complementary strategy supporting inspectors rather than as an independent system. As opposed to eliminating the human from the loop, the control architecture used in this study supports different levels of human input, focusing on robots with limited decision making and simple command and control. A robot generated map would serve as a cognitive workspace to provide the means to represent goals that are both meaningful to the robot and human operator. Inspectors performing DIV could potentially deploy robotic team members to build and log characterization maps of complex facilities.

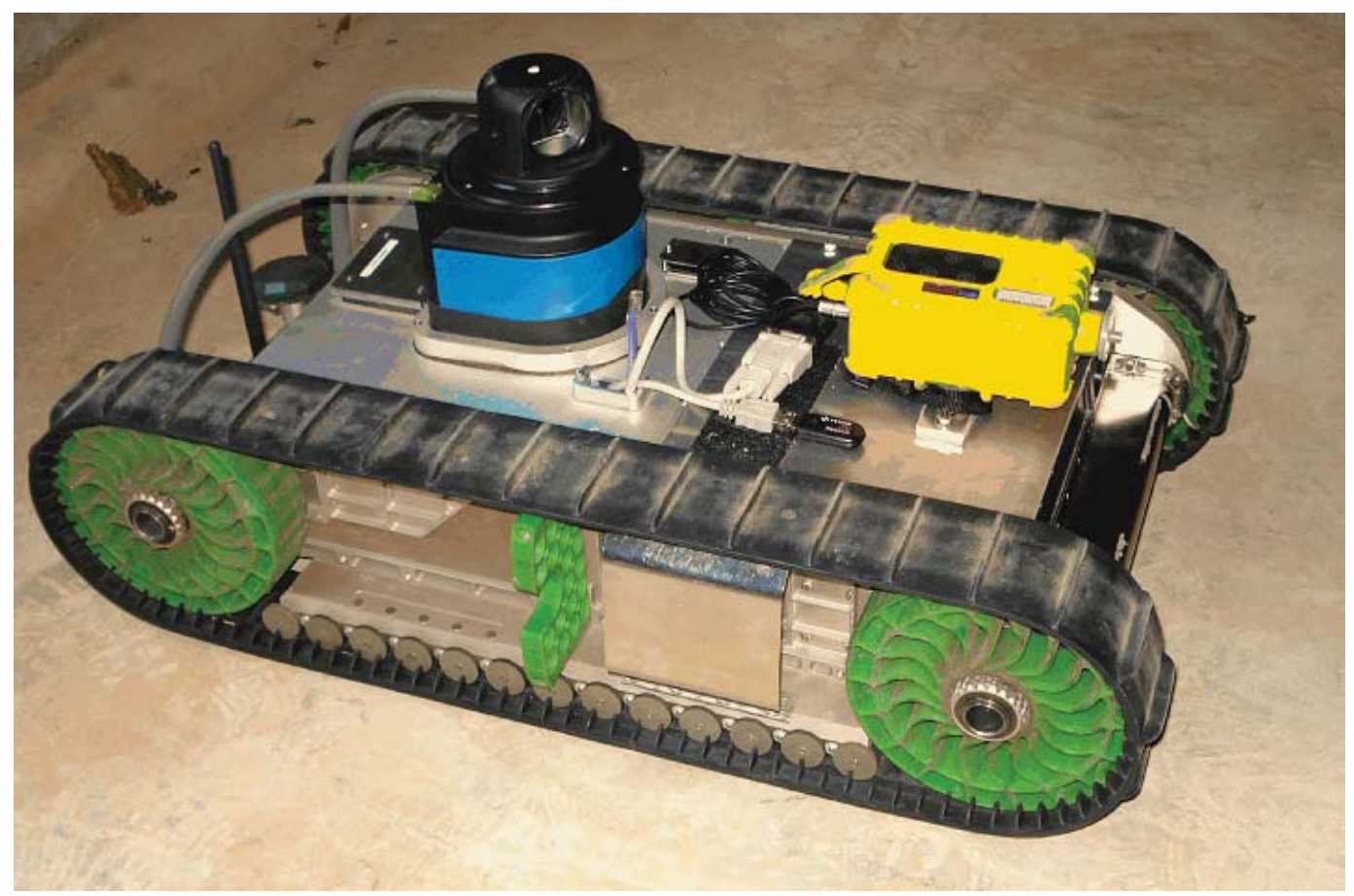

Figure 10: Miniature All Terrain Robotic Vehicle Developed for Hazardous Environment. (Approximately 1-meter in length) (Source-Idaho National Laboratory) 
Table 8: Robotics in Support of DIV Pros and Cons.

\begin{tabular}{|l|l|l|}
\hline $\begin{array}{l}\text { Robotics in } \\
\text { Support of DIV }\end{array}$ & $\begin{array}{l}\text { A variety of small custom-built robots with sensors for supporting verification of } \\
\text { nuclear facility design information and plant features and conditions. }\end{array}$ \\
\hline Pros & $\begin{array}{l}\text { A number of small custom-built robots have been developed for applications in } \\
\text { nuclear facilities, primarily to support emergency incident and accident assessment } \\
\text { and response. Such robots have been used at the damaged Three Mile Island and } \\
\text { Chernobyl nuclear power stations. Robots have the special feature of being capable } \\
\text { of accessing areas that are unsafe and inaccessible to safeguards inspectors and } \\
\text { other personnel. }\end{array}$ \\
\hline Cons & $\begin{array}{l}\text { Custom-built robots tend to be relatively expensive, although the value provided by } \\
\text { the robot depends on how badly one needs to access the normally inaccessible area. }\end{array}$ \\
\hline Comments & $\begin{array}{l}\text { The IAEA has most likely not pursued robots in support of DIV because they may } \\
\text { not be aware of the spectrum of options in this regard. Concerns have been } \\
\text { expressed by some nuclear plant operators that a robot used in a nuclear facility } \\
\text { could potentially get snagged and damage wiring or cabling. Further investigation } \\
\text { and consideration of special-built robots in support of DIV, especially for verifying } \\
\text { conditions and status in areas declared inaccessible due to high radiation or } \\
\text { radioactive contamination is warranted. }\end{array}$ \\
\hline Cost & $\begin{array}{l}\text { Rad-hard Robot in Support of DIV (Mark-I)* } \\
*(\text { Cost depends on robotic features specified) }\end{array}$ & \$300K \\
\hline
\end{tabular}

The spatial accuracy of the characterization maps is typically within $\pm 2 \mathrm{~cm}$ of the actual position and could be used to verify the physical accuracy of a facility against a blueprint that would not normally be accessible to the safeguards inspector, because of health and safety or radiation/contamination. Additionally, the characterization maps could be used in a historical comparison to see how sensor data levels change in a facility across time. Where inspectors have ready access to nuclear facilities and nuclear material processing areas, the use of robotics may not be competitive or justified. However, there appears to be a niche for using robotics in support of DIV, especially in areas that are inaccessible due to hazardous conditions, such as that found in high radiation areas or those heavily contaminated. A summary of the pros, cons, issues, and relative cost for the purpose of comparison is provided in Table 8 . 


\subsection{Outdoor Verification System (OVS) for Site Level DIV}

There is a need to verify nuclear facilities on the level of the entire site, in order to detect potentially undeclared nuclear facilities functionally linked to other facilities on the site, i.e., determine the full scope and capacity of existing facilities.

In addition to the need to verify the interior of nuclear facilities during DIV, there is the need to verify the extent of these facilities and to determine if they are functionally linked. This is very important for determining the size and scale of nuclear facilities and for confirming their processing capacity. In order to better verify nuclear facilities on the level of an entire nuclear site, JRC/Ispra developed the Outdoor Verification System (OVS). ${ }^{22}$ Like the 3DLR, the OVS is an infrared laser-based system used for surveying and mapping the topography of buildings and outdoor features in 3-dimensions. The system contains the laser emitter, receiver, and high speed integration electronics and on-board computer of the 3DLR, but the system has been modified with attaching rails and carriage to permit mounting on a vehicle, such as a Jeep or helicopter. The software has been modified to permit the collection of scan data while compensating for the movement of the vehicle and instrument. Consequently, the OVS can generate 3-dimensional maps and images of large structures viewed along the path of the vehicle. What this means is that the OVS can effectively map the exterior of facilities and capture the visible interconnecting process piping, ductwork, and connections to ancillary facilities in great detail and in three dimensions. The resolution of the OVS is such that it can see depressions in the soil from buried piping, equipment burial grounds, etc. Therefore, to some degree it could potentially detect areas below the surface that may be of interest to the inspector as well, in order to pinpoint the search for potential buried nuclear process equipment, piping, and material. A view of the OVS hardware compared side by side to the 3DLR is shown in Figure 11.

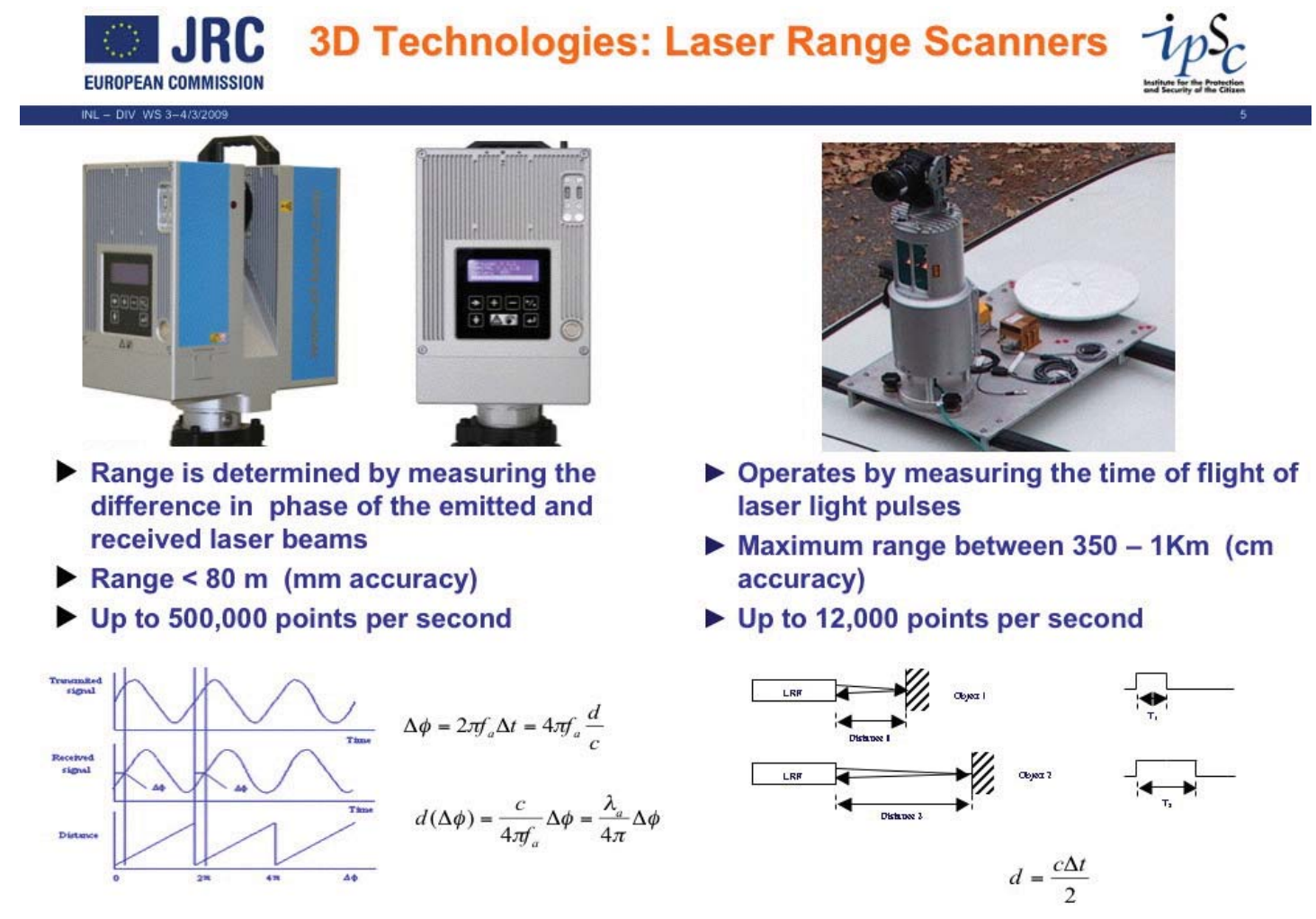

Figure 11: Comparison of the 3DLR (Left) and the OVS (Right). (Source - European Commission Joint Research Centre, Ispra, Italy) 
To demonstrate the OVS to IAEA inspectors, JRC/Ispra scanned the exterior of IAEA Headquarters at the Vienna International Centre (VIC) in Vienna, Austria, following the route and survey points as shown in Figure 12. Vignettes of the resulting three dimensional images are shown overlapping in Figure 13. The images are very clear and near photographic in quality, provided the OVS has a clear line-of-site access for the scanning laser beam. Most importantly, it has the critical advantage that the images are 3-dimensional and digitized. This means that the safeguards inspector can zoom into specific areas of interest to look at selected features in greater detail. While the OVS has not yet been used by IAEA safeguards inspectors on any significant level for DIV, the device appears to be highly useful for that purpose, especially for verifying the exterior of large nuclear facilities and the interconnections between nuclear facilities and ancillary structures on a nuclear site. Imagery from the OVS would be better than most satellite imagery commercially available to the IAEA. Imagery collected by the OVS during DIV would also allow the IAEA to make comprehensive computerized reference models of large and complex nuclear sites - especially those suspected of having undeclared nuclear activities and/or facilities. A summary of pros, cons, issues, and relative cost for the purpose of comparison is provided in Table 9.
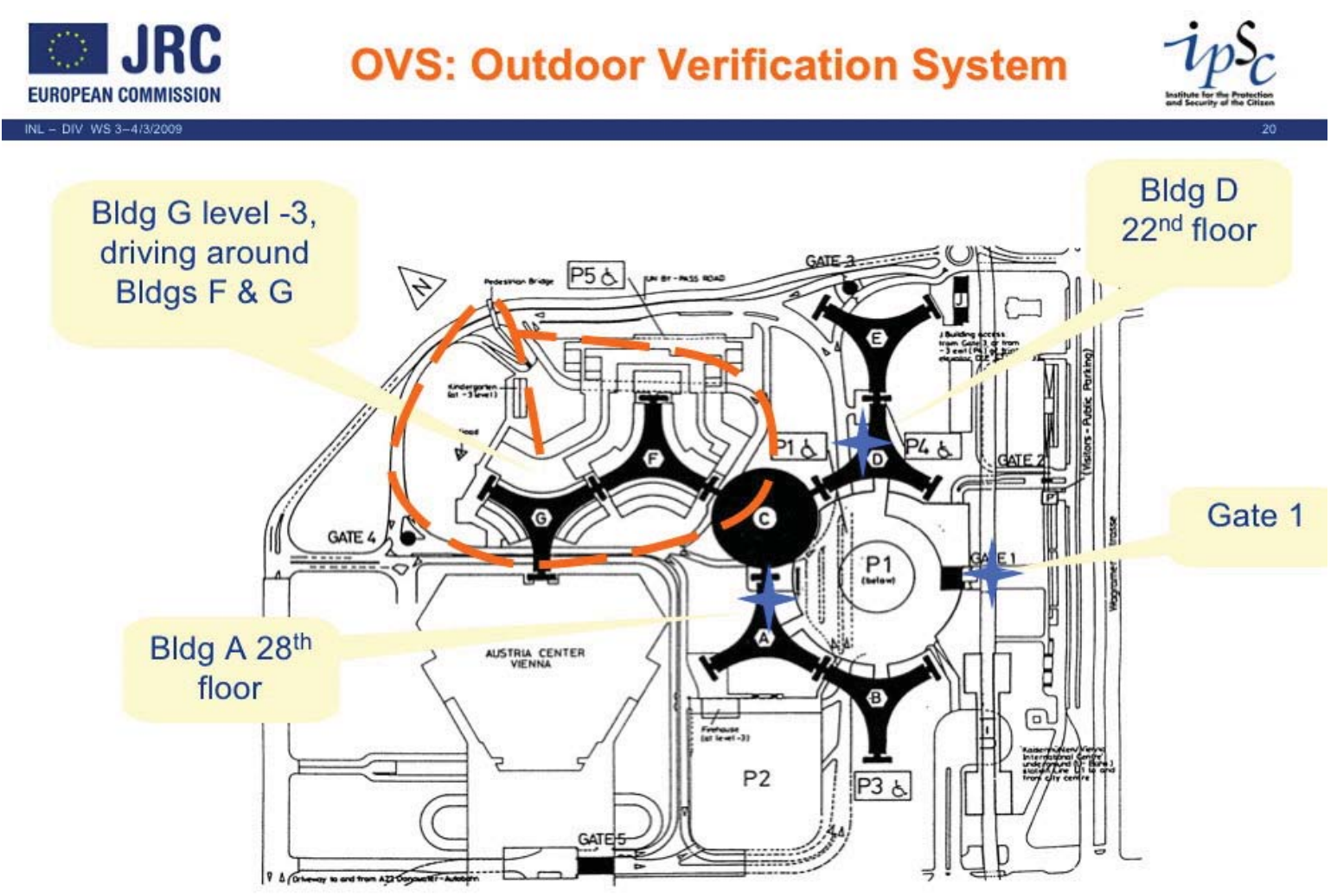

Figure 12: Scanning Route of the OVS for Surveying the Vienna International Centre (VIC). (Source - European Commission Joint Research Centre - Ispra, Italy) 


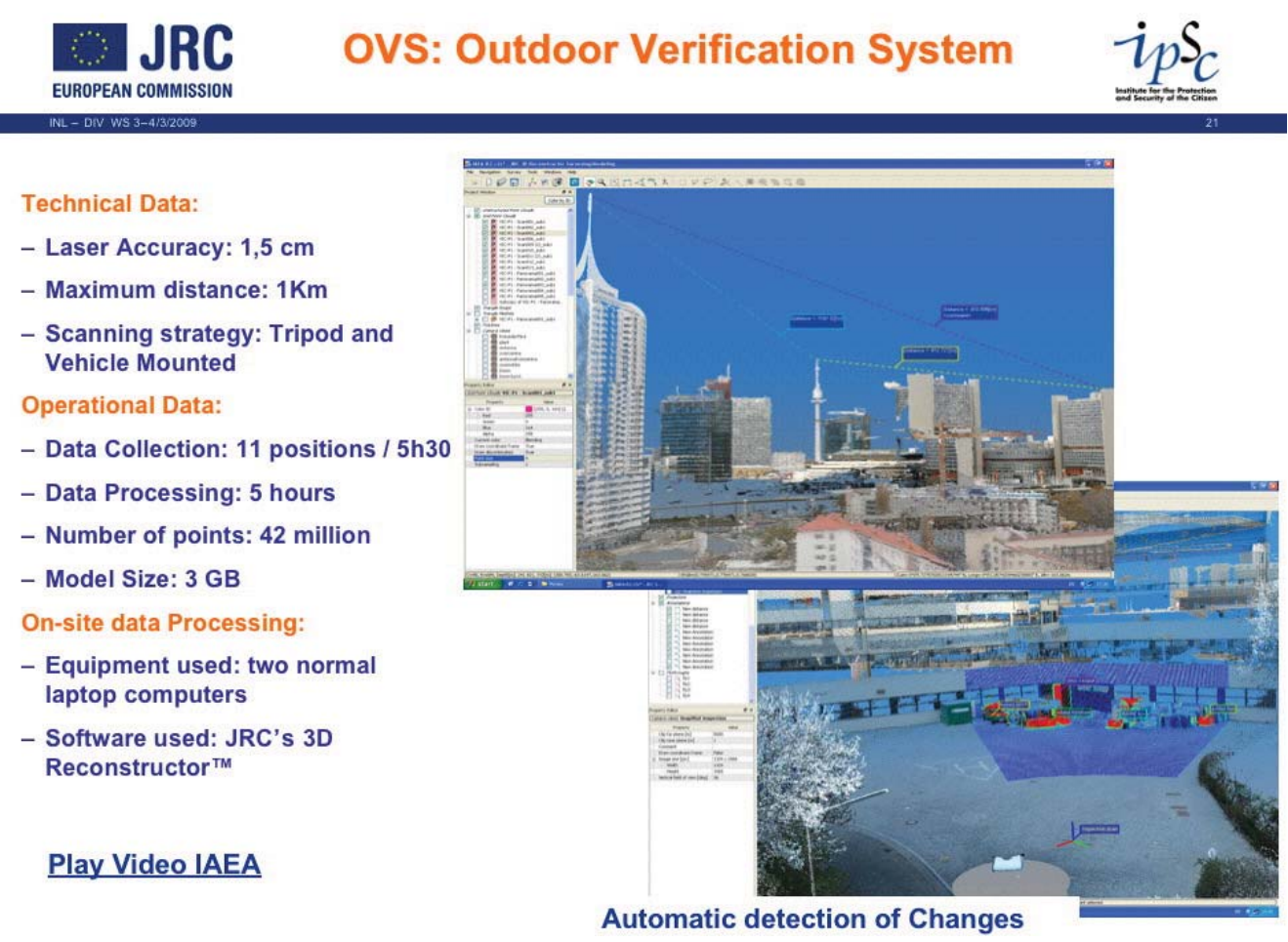

Figure 13: 3-Dimensional Images of the VIC Using the OVS.

(Objects highlighted in red were detected by the Change Detection Software.)

(Source - European Commission Joint Research Centre - Ispra, Italy)

\section{Table 9: Outdoor Verification System (OVS) Pros and Cons.}

\begin{tabular}{|l|l|l|}
\hline Outdoor & $\begin{array}{l}\text { Infrared laser-based survey tool based on 3DLR technology used on a mobile } \\
\text { platform. The OVS can be used to map the exterior of large and complex nuclear } \\
\text { facilities in three dimensions and could support the verification of the design } \\
\text { information for a complete nuclear complex at the site level. }\end{array}$ \\
\hline Pros & $\begin{array}{l}\text { The OVS has been developed by JRC/Ispra and initially demonstrated and tested in } \\
\text { Ravenna, Italy, and at the Vienna International Centre (VIC) in Vienna, Austria. It } \\
\text { appears to be as effective as the well proven 3DLR with the added benefit that it can } \\
\text { scan and map large and complex nuclear facilities and sites. }\end{array}$ \\
\hline Cons & $\begin{array}{l}\text { The IAEA has not yet extensively used the system and appears to need additional } \\
\text { demonstration of the system's utility for supporting DIV of large and complex } \\
\text { nuclear facilities and sites. }\end{array}$ \\
\hline Comments & $\begin{array}{l}\text { An OVS has not been purchased by or provided to the IAEA. It has not been tested } \\
\text { by the IAEA and is not yet a category-B rated instrument-approved for conditional } \\
\text { use. In addition, a significant number of IAEA inspectors have not yet been trained } \\
\text { in the use of the instrument as well. Despite these points, the OVS would appear to } \\
\text { be a highly useful and effective instrument for supporting the DIV of large and } \\
\text { complex nuclear facilities and sites. Further demonstration of the use of this } \\
\text { instrument for nuclear DIV applications by DOE/NNSA could potentially } \\
\text { encourage broader use of this instrument by the IAEA. }\end{array}$ \\
\hline Cost & $\begin{array}{l}\text { Outdoor Verification System (OVS) (Mark-I)* } \\
\text { *(Does not include the cost of a locally provided vehicle, which } \\
\text { may be leased) }\end{array}$ & \begin{tabular}{l} 
\$200K - \$250K \\
\hline
\end{tabular} \\
\hline
\end{tabular}




\section{OUTSTANDING DIV NEEDS}

\subsection{Additional Equipment and Training}

From the discussions at the DIV Workshop, the attendees noted that despite the wide utility and proven performance of the 3DLR in support of DIV, its application by the IAEA for this purpose was limited. From discussions with the system developer, Mr. Sequeira of JRC/Ispra, this appeared to be because the IAEA has only three systems available for use. One system is permanently situated at RRP for periodic re-verification of design information. However, even this unit is not redeployed and used at other locations in Japan (i.e., at the plutonium processing site at Tokaimura). The main limitations seem to be the number of 3DLR systems, and the number of inspectors who have been trained in its use. We estimate the number of trained users to be approximately 40 inspectors, with perhaps 30 remaining after deducting for retirement and staff attrition during this period. For this reason, the acquisition, or donation of additional 3DLR systems to the IAEA appears to be an urgent need, together with the training of additional inspectors in the use of this system. What is also important to note is that the IAEA does not possess any of the redesigned Mark-II (2008) 3DLR systems, which does not have the deficiencies noted during the original trial of the 3DLR in 2003. IAEA inspectors have also not been trained in the new Mark-II system. Both these issues are urgent safeguards needs that the participants thought DOE/NNSA could help address.

\subsection{New and Improved Equipment and Associated Training}

There is a need to address other aspects that perhaps can only be addressed with new technology. Combining the CCI or Gamma Camera with the 3DLR could help address the need to verify process piping and vessels, which may be processing radioactive solution, thereby confirming the extent of the nuclear process or facility. Enhanced GPR could also be used to detect concealed piping and process vessels, although the extent to which it can is still in need of further demonstration. Regardless, there are a number of such tools which could address the main limitations of the 3DLR (i.e., peering into blocked or concealed locations). The IAEA does need to address this issue, perhaps not for every facility, but they should have the tools to peer into concealed spaces as required. This new equipment would necessitate specialized training as is conducted with the 3DLR. There are approximately 210 safeguards inspectors in Operations Divisions-A, B, and C in the Department of Safeguards. A suitably large number of inspectors should be trained in any new equipment, to permit broad and full use of the equipment and operational flexibility.

\subsection{Engineering Training for DIE/DIV (Blueprint Reading for Inspectors)}

For inspectors to compare computerized scans from the 3DLR with the Operator's engineering blueprints, inspectors need to be fluent in reading engineering drawings - i.e., mechanical, electrical, instrumentation, arch-structural, process piping installation, and process vessel fabrication drawings. While this is standard training for most engineers, it is not for safeguards inspectors who were trained as nuclear physicists and instrument specialists, etc. To address this need, the workshop participants recommended that short courses be conducted at the IAEA to provide this background. The team envisions that short three-day to one-week courses could effectively address this training deficiency. This would provide safeguards inspectors the additional tools for more effectively reading and interpreting design drawings and information provided by the nuclear facility operator. 


\subsection{Portable Reference Facility Models}

During the process of DIV, what has become apparent is that it would be valuable to have the reference design information handy. If the design information is primarily in the form of drawings, this becomes awkward and cumbersome. The Mark-II 3DLR allows the inspector to bring stored scans and design information into the facility in the onboard computer, although the operator and national authorities would need to control the uploading of this information from a controlled hard-drive or disk. But it is possible to bring reference information into the facility already preloaded in the 3DLR. As has been discussed, there are also other means to address this need. Facility reference files could be created using VR rendering, based on the same design information, drawings, and photos normally provided to the IAEA. In principle, an inspector could keep a computerized reference file on a resident laptop computer, stored in a secured file cabinet at the facility, and use this laptop during DIV, maintaining a continuous string of DIV records at the facility. This would allow subsequent inspectors to see what had been verified before with special notation regarding particular items of interest or requiring follow-up. One challenge in this regard is that it takes more time than considered optimal to construct VR reference files. If this process could be made more efficient, this could be a very effective tool in support of DIV. In any case, the use of VR reference facility models for pre-inspection briefing and training appears to be a compelling need, and a potential that should be brought to the attention of the IAEA. Considering how the reference facility files are becoming more and more portable, as the storage capacity of portable computers increases, it may be possible in the future to carry a tablet personal computer directly into the facility with the reference facility model and all relevant design information and records of previous DIVs.

\subsection{Automated Change Detection Tools}

The IAEA uses Change Detection Software (CDS) in reviewing video surveillance media and onboard in the 3DLR system. But the IAEA does not yet use CDS for comparing existing reference Polaroid photographs in support of DIV. This is now possible and should be considered for wider application. With tools demonstrated at this workshop, it is possible to scan existing reference Polaroid photos and take new digital photographs of current facilities and process equipment to automatically detect changes. While, the inspector would still need to interpret if these changes are safeguards relevant, this is still much more effective than relying on the alertness and awareness of the inspector to detect these changes with the naked eye. This tool could also potentially support the IAEA Limited Frequency Unannounced Access (LFUA) conducted at enrichment plants, because it remains very challenging to detect changes in the mind-numbingly complex and repetitive cascade header and utility piping. In the future, it may be possible to pre-program some of the more common process equipment systems into the image data base, so that the computer could automatically provide support in determining whether the changes noted are safeguards relevant; although, we may have to continue to rely on the inspector to make this assessment for the foreseeable future.

\subsection{Equipment for Detecting Concealed or Buried Nuclear Process Equipment}

The IAEA continues to have a need to detect concealed process piping and vessels, or piping and vessels that may be extensions of an undeclared nuclear chemical processing facility. The use of the Gamma Camera with the 3DLR, OVS, and enhanced GPR would help address these needs. All of these systems, though, require further demonstration, especially in actual field locations to better evaluate their benefit and effectiveness. Nonetheless, the IAEA does have this need and it is still largely unaddressed. 


\subsection{Modern Methods for Storing, Handling, and Securing Design Information}

The extensive DIE/DIV experience at the Rokkashomura Reprocessing Plant (RRP) and in Europe underscores the need to handle safeguards relevant design information in a secured and protected manner. This is because it most likely contains proprietary and safeguards sensitive data. Current methods include: (1) limiting the distribution of design information; (2) labeling such information clearly in red as "Safeguards Confidential;" (3) storing the information in IAEA approved file cabinets or secured enclosures; and (4) keeping this material under the joint seals of the IAEA and national authorities. While these methods have been effective, one should consider the migration from paper design information formats to electronic and computer media that will also require identification, control, and protection. It is likely that the traditional methods as currently employed by the IAEA will continue to be the norm, especially at the smaller and less sensitive facilities. However, as more and more computerized design information and verification information is gathered, both the IAEA and the facility operators and national authorities need to consider how best to address this problem. This issue may even be at the root of why the 3DLR systems purchased by the IAEA are not more widely used (i.e., concern regarding the security and control of the verification data). The Workshop Team thinks that this is still an area that requires greater discussion between the IAEA inspectorate, IAEA member states, nuclear facility operators, and national nuclear authorities. More effective and efficient DIVs can be performed with the modern tools as has been described, but only if the data security issues are addressed to everyone's mutual satisfaction. 


\section{SUMMARY OF WORKSHOP FINDINGS}

\subsection{Workshop Findings}

From the presentations and panel discussion, the Workshop Team deduced the following:

1. IAEA inspectors continue to perform DIV using primarily hand-tools, blueprints, photographs and visual observation. Modern techniques exist to dramatically improve the DIV activity.

2. The 3DLR, developed by JRC/Ispra and used by the IAEA, is one such modern tool for performing DIV, as demonstrated at RRP from 2002 to 2006.

3. Broader use of the 3DLR at the IAEA appears to be limited, for lack of additional instruments and inspector training in use of the instrument. The IAEA possesses only three 3DLR units of the older original Mark-I design, one of which is permanently resident at the RRP Site in northern Japan. The Workshop Team estimates that of the approximately 250 designated inspectors at the IAEA, only about 40 have been trained in the use of this instrument, and of those perhaps only 30 remain at the IAEA.

4. DOE/NNSA should encourage broader use of the 3DLR by the IAEA, especially in Japan, where a resident instrument is pre-positioned, and at other large and complex nuclear sites where additional systems could be pre-positioned.

5. Other technologies show promise for improving the effectiveness and efficiency of performing DIV.

6. The OVS, developed by JRC/Ispra, is a mobile variant of the 3DLR. It permits the computerized mapping and verification of entire nuclear sites from the platform of a Jeep or other vehicle. The OVS provides detailed three dimensional mapping at a very local level that shows trenches, burial grounds, and connective features between nuclear facilities on a site. It would address the need for verifying design information at the broader site-level.

7. Researchers at LLNL, LBNL, and ORNL have demonstrated that a gamma camera can be combined with the 3DLR to address the need to detect undeclared piping and vessels containing gamma emitting nuclear material. This instrument could potentially be further developed to detect the presence of highly-enriched uranium (HEU) in nuclear facilities.

8. PNNL has demonstrated enhanced GPR to visualize buried objects in three dimensions, which could address the safeguards need to detect buried or concealed process vessels and/or piping during DIV.

9. LANL, INL, and ORNL have demonstrated virtual reality (VR) software tools to address the need for preparing portable facility reference models for use during DIV. Such tools could also be used for facility specific pre-inspection briefing and inspection training.

10. INL has demonstrated Change Detection Software (CDS) for planar images that could be used with scanned images of older existing Polaroid photos and other design information to detect changes on a laptop, after taking a digital photograph of the current installation. This technology would allow a more systematic review by the inspector during DIV, especially where only older reference photos are available.

11. Future developments in support of DIV should consider a heads-up viewer and display that would access a portable computer with reference DIV information on demand. The heads-up viewer and display would be able to recognize existing features and automatically compare them against the 
reference images in the computer, with safeguards relevant changes would be highlighted in the viewer.

12. Model responses to the IAEA DIQ have not been revised since 1978. DOE previously provided these model DIQ responses through the U.S. Support Program to the IAEA to aid others in the proper completion of the DIQ. NNSA should consider updating these model DIQ responses by facility type.

13. The safeguards relevant Essential Equipment Lists (EEL) compiled for each facility should be updated by the IAEA. 


\section{CONCLUSIONS AND RECOMMENDATIONS TO NNSA}

\subsection{Conclusions}

The NNSA Office of International Regimes and Agreements sponsored a technical workshop within the U.S. DOE National Laboratory Complex to determine how to improve the effectiveness and efficiency of the IAEA nuclear facility design information examination and verification activity (DIE/DIV). This was done under the Advanced Safeguards Approaches (ASA-100) Project and in support of the Next Generation Safeguards Initiative. From the workshop discussions and presentations, the Team concluded the following:

- The DIE/DIV activity remains an important safeguards measure used by the IAEA to verify that nuclear facilities are being built and operated by the facility operator as declared by the national authorities, i.e., that the facility function or capacity has not been altered.

- As currently conducted by the IAEA, the DIE/DIV activity could be made more effective and efficient.

- The DIE/DIV activity relies heavily on individual inspector training, knowledge, and experience. In the near-term, additional training could help standardize how inspectors perform the DIE/DIV. Tools, such as the 3DLR, also help systematize the process and improve the effectiveness of the DIE/DIV in detecting safeguards relevant changes. However, the IAEA only has three 3DLR units, one of which is permanently stationed at the Rokkashomura Reprocessing Plant in Japan. Additionally, the IAEA only has the older Mark-I 3DLR (ca. 2003) and none of the newer Mark-II (2008) models.

- As nuclear facilities become larger and more complex, the IAEA must be able to perform DIE/DIV more efficiently to verify that the safeguards relevant aspects and features of the facility are as declared by the facility operator and national authorities. This was one of the major conclusions from the 10-year effort of performing DIE/DIV at the Rokkashomura Reprocessing Plant in Japan.

- IAEA inspectors need to have ready access to design information and previous DIE/DIV reports in the field while performing the DIE/DIV. This need could potentially be met with portable laptop or tablet personal computers containing the design information on a secured and protected file.

- IAEA inspectors need to be able to discern safeguards relevant changes to the nuclear facility during the DIE/DIV activity. This need could be met in the near term with additional training, and potentially in the future with new tools that incorporate automated image recognition and built-in Change Detection Software (CDS), such as utilized by the 3DLR. However, the image recognition feature could also embody an automated and accessible computerized catalogue of known equipment types and features to aid in this process.

- The IAEA needs the ability to detect concealed process equipment and piping, which could potentially be detected during DIE/DIV if the right tools were available. Development efforts have focused on combining the 3DLR with a gamma camera to detect undeclared process piping and nuclear material. The use of enhanced ground penetrating radar (GPR) is also possible, as had been demonstrated in detecting buried waste drums and vessels at the DOE Hanford Site. This is still an area that requires additional development and demonstration to prove that the tool could be used practically by the IAEA for DIE/DIV.

- The DIE/DIV activity is fundamentally based on the quality of the information provided by the facility operator through the SSAC to the IAEA in the form of the IAEA Design Information Questionnaire (DIQ). U.S. DOE had previously provided model responses and 
examples to the IAEA, to help standardize the process and raise the quality of the information provided via the DIQ. These models are now thirty years old and are in need of being updated.

- The DIE/DIV activity depends on the IAEA Safeguards Facility Officer maintaining a current and relevant Essential Equipment List (EEL) of safeguards relevant equipment at the facility.

\subsection{Recommended Next Steps}

Based on the workshop findings and conclusions, the Team recommends the following next steps to NNSA to help the IAEA improve the effectiveness and efficiency of the DIE/DIV activity:

Near Term - (Within the next 6 Months to 1 Year)

- Provide additional training via the United States Support Program to the IAEA to help IAEA safeguards inspectors read engineering mechanical, piping, instrument, and architectural blueprints, drawings, and process flow schematics more proficiently. The estimated cost of providing additional training to the IAEA inspectors in the reading of engineering blueprints is $\$ 100 \mathrm{~K}$ for one year.

- Provide financial support to the IAEA to upgrade the three existing 3DLR units from the Mark-I (2003) model to the Mark-II (2008) model. According to the developer from $\mathrm{JRC} / \mathrm{Ispra}$, cost of this upgrade is estimated to be on the order of $\$ 50 \mathrm{~K}$ per unit, for a one time total cost of $\$ 150 \mathrm{~K}$.

- Provide financial support to the IAEA to acquire additional Mark-II 3DLR units. If the IAEA had three additional 3DLR units, one unit could be prepositioned in each major region of the world where the IAEA inspects. This would reduce the cost of shipping 3DLR units to and from Vienna, and would minimize the likelihood of damage resulting from shipping. At an estimated cost of $\$ 200 \mathrm{~K}$ per unit, the total cost would be $\$ 600 \mathrm{~K}$.

- Provide additional training via the USSP to the IAEA in the use of the modernized Mark-II 3DLR. Of the estimated 40 safeguards inspectors trained in the use of the 3DLR, most were trained in the use of the older Mark-I model, and of those, as many as 10 have left the IAEA. The IAEA needs intense training in the use of the Mark-II model so that use of the 3DLR is not hindered for lack of trained personnel. It is recommended that this training be provided by knowledgeable staff at JRC/Ispra, with the support of experienced DOE National Laboratory staff. The estimated cost of providing additional training to the IAEA in using the Mark-II 3DLR and training a larger group of inspectors is $\$ 100 \mathrm{~K}$ for one year.

- Provide updated model responses to the IAEA DIQ through the United States Support Program to the IAEA, for each major type of nuclear facility, as had been provided previously in 1978. The estimated cost for updating the model responses to the IAEA DIQ for a series of 10 types of nuclear facilities is $\$ 100 \mathrm{~K}$ total.

- Recommend to the IAEA Department of Safeguards to update the Essential Equipment Lists (EEL) for facilities under IAEA safeguards.

- Recommend to the IAEA that they systematically digitize old design information, such as Polaroid photographs, and implement the use of Change Detection Software (CDS). If the older reference information were digitized, it could be stored on resident laptop computers, and/or hard disks at the facility under seal. It could then be subsequently compared to new digital photos acquired during current DIE/DIV activities, and compared using CDS. This process would be far less subjective and more systematic than the use of hardcopy photos and individual inspector visual observation. The estimated cost of demonstrating CDS to support DIE/DIV for a group of three nuclear facilities is $\$ 50 \mathrm{~K}$. 


\section{Medium Term - (Within 1 to 3 Years)}

- Fund the National Laboratories to demonstrate the use of the JRC-developed Outdoor Verification System (OVS) in a practical DIE/DIV exercise to verify an entire nuclear site. This demonstration could be performed at a selected U.S. DOE site with the support of staff from JRC/Ispra and with the attendance of key staff from the IAEA Department of Safeguards. The purpose of the demonstration would be to show the utility of the OVS in verifying complete nuclear sites and detecting the functional linkage between nuclear and ancillary facilities. The estimated cost of demonstrating the OVS to support DIE/DIV at a DOE nuclear site is $\$ 100 \mathrm{~K}$.

- Fund the National Laboratories to demonstrate a modified 3DLR with gamma camera (Gamma LIDAR) in a practical DIE/DIV exercise at a DOE National Laboratory facility. The demonstration should be conducted in a lifelike DIE/DIV scenario. The performance of the Gamma LIDAR (3DLR \& gamma camera) to detect undeclared radioactive process piping should be evaluated, as well as the ease of using and moving the experimental prototype through the nuclear facility. Facilities which could be used for the test include hot cell examination facilities and research reactors. The estimated cost of further developing and demonstrating the Gamma LIDAR in support of DIE/DIV is $\$ 500 \mathrm{~K}$.

- Fund the National Laboratories to demonstrate the use of enhanced ground penetrating radar (GPR) in a practical DIE/DIV exercise at a DOE National Laboratory facility. The demonstration should be conducted in a lifelike DIE/DIV scenario to detect concealed process piping in concrete walls and undeclared piping and vessels buried within 1-3 meters of top soil. The performance of the GPR to detect concealed process piping and vessels should be evaluated, as well as the ease of using and moving the experimental prototype. The estimated cost of developing and demonstrating enhanced GPR in support of DIE/DIV is $\$ 500 \mathrm{~K}$.

- Consider funding the National Laboratories to develop a portable heads-up viewer for conducting DIE/DIV. The need for such a device would need to be affirmed by the IAEA, but it is technically possible to develop a headset that captures digital images by the wearer and compares these images against the computerized reference files for the facility, using change detection software. Additionally, the reference computer files could include the shape and configuration of typical pieces of process equipment that are of safeguards importance, such as uranium enrichment centrifuges, solvent extraction columns, mixer-settlers, etc., to help the user detect the presence of undeclared safeguards relevant equipment. While such a device is conceptual at this stage, the components and functions have been demonstrated separately. The heads-up viewer could also incorporate a radiation detector/personnel dosimeter that would allow the user to detect and confirm the presence of high-radiation fields, which would protect the inspector when the facility is hot and operational. The benefit of such a device is that it would allow each inspector performing DIE/DIV to function at an equivalent high-level of performance. The estimated cost of developing and demonstrating a portable heads-up viewer to support DIE/DIV is estimated at $\$ 300 \mathrm{~K}$. 


\section{REFERENCES}

1. International Atomic Energy Agency: Treaty on the Non-Proliferation of Nuclear Weapons, (as reproduced in) INFCIRC/140, Vienna, Austria, April, 1970.

2. International Atomic Energy Agency: The Structure and Content of Agreements between the Agency and States Required in Connection with the Treaty on the Non-Proliferation of Nuclear Weapons, INFCIRC/153 (corrected), Vienna, Austria, June, 1972.

3. International Atomic Energy Agency: "Strengthening of Agency Safeguards: The Provision and Use of Design Information," IAEA Board of Governors Report \# GOV/2554/Attachment 2, (Revision-2), April, 1992.

4. International Atomic Energy Agency: IAEA Safeguards Glossary - 2001 Edition, International Nuclear Verification Series No. 3, Vienna, Austria, 2002.

5. International Atomic Energy Agency: The Agency's Safeguards System, INFCIRC/66, para. 30-32, revised version, 1968.

6. U.S. Department of Energy, National Nuclear Security Administration: Next Generation Safeguards Initiative, NNSA Office of Nonproliferation and International Security (NA 24), Washington D. C., October, 2007.

7. International Atomic Energy Agency: "IAEA Annual Report for 2007," IAEA Report to the General Conference \#GC (52)/9, Vienna, Austria, 2008, page 88.

8. International Atomic Energy Agency: Safeguards Manual - Parts SMI and SMC, Chapter SMI 4.1, "Design Information Examination and Verification," October, 2003.

9. International Atomic Energy Agency, Department of Safeguards: Safeguards Manual - Parts SMI and SMC, SMI-4.1, "Design Information Examination and Verification," Vienna, Austria, October, 2003.

10. Durst, P. C.: Personal communication, April, 2009.

11. International Atomic Energy Agency (IAEA): The Structure and Content of Agreements between the Agency and States Required in Connection with the Treaty on the Non-Proliferation of Nuclear Weapons, INFCIRC/153 (corrected), Paragraph 47, Vienna, Austria, June, 1972.

12. Sequeira, V., et al.: "JRC Technology Development," European Commission Joint Research Centre, Ispra, Italy, Presentation made in Idaho Falls, ID, JRC\# INL-DIV-WS 3-4/3/2009, March 3 \& 4, 2009.

13. Sequeira, V., et al.: "3D Laser Range Finder for Design Information Verification in the Rokkasho Reprocessing Plant," European Commission Joint Research Centre, Fact-sheet, Ispra, Italy, 2006.

14. Mihailescu, L., et al.; "A 3D Gamma Information Verification Scanner (3D-GIVS) for Inspection and Characterization of Nuclear Materials," Lawrence Livermore National Laboratory, Livermore, CA, June, 2007.

15. Dougan, A., et al.: "New and Novel Non-destructive Neutron and Gamma-Ray Technologies Applied to Safeguards," U.S. DOE Lawrence Livermore National Laboratory, Presentation URCL-PRES-235638, Presented in Idaho Falls, ID, March 3 \& 4, 2009.

16. Durst, P. C.: Personal communication, May, 2009. 
17. Michel, K., et al: "Projected Virtual Reality for Use in Design Information Verification," U.S. DOE Los Alamos National Laboratory, Presented at Idaho Falls, ID, March 3 \& 4, 2009.

18. Marble, J.L., Bruemmer, D.J., and Few, D.A.: "Lessons Learned from Usability Tests with a Collaborative Cognitive Workspace for Human/Robot Teams," In Proc. IEEE Conf. on Systems, Man, and Cybernetics, 2003.

19. Bruemmer, D.J., et al.: "Mixed-Initiative Control for Remote Characterization of Hazardous Environments," Proc. HICSS 2003, Waikoloa Village, Hawaii, January 2003.

20. Abbott, K.A., Slotte, S.M., \& Stimson, D.K.: Federal Aviation Administration Human Factors Team Report, "The Interfaces Between Flight-crews and Modern Flight Deck Systems," Federal Aviation Administration, Washington, DC, Tech. Rep. 1996; from http://www.faa.gov/avr/afs/interfac.pdf.

21. Espinosa, J.A., Cadiz, J., et al.: "Coming to the Wrong Decision Quickly - Why Awareness Tools Must be Matched with Appropriate Tasks," Proc. of the Human Factors in Computing Systems, Computer/Human Interaction (CHI) Conference, ACM Press, 2000.

22 Sequeira, V., et al.: "JRC Technology Development," European Commission Joint Research Centre, Ispra, Italy, Presentation made in Idaho Falls, ID, JRC\# INL-DIV-WS 3-4/3/2009, March 3 \& 4, 2009. 